SVERIGES RIKSBANK

WORKING PAPER SERIES

184

Exploring Interactions

between Real Activity and the Financial Stance

Tor Jacobson, Jesper Lindé and Kasper Roszbach APRIL 2005 
WORKING PAPERS ARE OBTAINABLE FROM

Sveriges Riksbank • Information Riksbank • SE-103 37 Stockholm Fax international: +4687870526

Telephone international: +4687870100 E-mail: info@riksbank.se

The Working Paper series presents reports on matters in the sphere of activities of the Riksbank that are considered to be of interest to a wider public.

The papers are to be regarded as reports on ongoing studies and the authors will be pleased to receive comments.

The views expressed in Working Papers are solely the responsibility of the authors and should not to be interpreted as reflecting the views of the Executive Board of Sveriges Riksbank. 


\title{
Exploring Interactions between Real Activity and the Financial Stance*
}

\author{
Tor Jacobson Jesper Lindé Kasper Roszbach \\ Sveriges Riksbank Working Paper Series \\ No. 184 \\ April 2005
}

\begin{abstract}
In this paper we empirically study interactions between real activity and the financial stance. Using aggregate data we examine a number of candidate measures of the financial stance of the economy. We find strong evidence for substantial spillover effects on aggregate activity from our preferred measure. Given this result, we use a large micro data-set for corporate firms to develop a macro-micro model of the interaction between the financial and real economy. This approach implies that the impulse responses of a given aggregate shock will depend on the portfolio structure of firms at any given point in time.
\end{abstract}

Keywords: Default-risk models; Business Cycles; Financial Stability; Price stability; Financial and real economy interaction

JEL: C41, G21, G33, G38

\footnotetext{
${ }^{*}$ Research Department, Sveriges Riksbank, 10337 Stockholm. We have benefitted from comments by participants at the "Regulation and Financial Stability Conference" at the Federal Reserve Bank of Atlanta (September 23-24, 2004), especially our discussant Charles Evans. Moreover, we have benefitted from presentations at the BIS 2003 autumn economist meeting on "Investigating the relationship between the financial and real economy", University of Verona and the Bank of England workshop on macro stress testing. Special thanks to Rikard Nilsson for superb research assistance. The views expressed in this paper are solely the responsibility of the authors and should not be interpreted as reflecting the views of the Executive Board of Sveriges Riksbank.
} 


\section{Introduction}

In this paper we empirically study the interactions between Swedish firms' balance sheets and the evolution of the Swedish economy. Most economists would consider it trivially true that macroeconomic conditions influence the state of the firms' balance sheets: good times result in prosperous firms with strong balance sheets, likewise a slowdown in the economy will be reflected by weak balance sheets. In that same view, the evolution of the macroeconomy will ultimately be determined by its firms' relative successes. Nevertheless, quantifying such relationships has turned out to be non-trivial. Most research has focused on either identifying the impact of macroeconomic conditions on firms' balance sheets, or the consequences of firms' balance sheets (generally through a bank channel) on the macroeconomy. The purpose of this paper is to explore the interaction and feedback between firms' balance sheets and the macroeconomy. It turns out that by using aggregate credit risk, approximated by firms' bankruptcy frequency over time, we find a useful link between the micro and the macro perspective.

Among policymakers, there appears to exist a broad consensus that market imperfections and instability in the financial sector can have significant and long-lasting effects on the real economy, cf. Lowe (2001). For academics, however, the role of the financial sector and credit in the macroeconomy has been a source of frequent debate, with some economists, see e.g. Poole (1993) arguing that credit only plays a role of its own in periods of financial crises. Others, see e.g. Bernanke (1993) and Calomiris and Hubbard (1989), hold that credit markets generally and continuously affect the macroeconomy through the so called credit channel.

Bernanke and Gertler (1995) describe the credit channel as "set of factors that amplify and propagate conventional interest rate effects" of monetary policy through endogenous changes in the external finance premium. Adherents of this "credit view" have identified two main linkages between central banks' actions and credit markets: a (borrowers')balance-sheet channel and a bank lending channel. ${ }^{1}$ The first link stresses the importance of borrowers' balance sheets and income statements, acknowledging that changes in monetary policy will have an impact on variables such as borrowers' net worth, cash flow and liquid assets. A second transmission mechanism focuses on the potential effect of monetary policy on the supply of loans by financial institutions. A common premise is, however, that frictions interfere with the smooth functioning of financial markets, creating a wedge between between the cost of externally raised funds and

\footnotetext{
${ }^{1}$ The balance sheet channel has sometimes also been called the broad credit channel. See for example Repullo and Suarez (2000).
} 
the opportunity cost of internal funds.

A large number of studies has explained and tested the mechanisms by which shocks to the financial sector are propagated into the real sector of the economy and found evidence in support of the existence of a balance-sheet channel. As far as the bank lending channel is concerned, the evidence in favor and against is still very much under debate. One of the studies that revived the debate on the balance-sheet channel is Bernanke (1983). In his study of non-monetary effects of the financial crisis during the Great Depression, he contends that the financial crisis of the 1930 's " affected the macroeconomy by reducing the quality of certain financial services, primarily credit intermediation", which in its turn disrupted the normal flow of bank credit. He also brings forward evidence of how the increase in defaults and bankruptcies and the progressive erosion of borrowers' collateral relative to their debt burdens during this period increased the cost of credit intermediation. Banks reacted to these changes by stopping to make loans to lower-quality investors, to which they had lent before. ${ }^{2}$ The events in the financial sector ultimately affected the bearing of the macroeconomy because the resulting higher effective cost of credit reduced businesses demand for current-period goods and services. An analysis of the determinants of output by Bernanke shows that two proxies for the financial crisis - changes in the deposits of failing banks and changes in the liabilities of failing businesses have substantial additional explanatory power for the growth rate of industrial production. In related work Coe (2002) use a Markov switching model to estimate conditional probabilities of a financial crisis occurring. He finds that these estimated probabilities have additional explanatory power in an model of real output, evidence that supports Bernanke's findings. Bernanke and Gertler (1989) develop a small model in which they use the inverse relationship between borrower net worth and the agency costs of investment to explain why changes in the condition of borrowers' balance sheets can be a source of business cycle fluctuations - without any financial crisis preceding the shocks. ${ }^{3}$ In a companion paper, Bernanke and Gertler (1990) also argue that financial factors can have quantitatively significant real effects by demonstrating how changes in the creditworthiness of borrowers affect investment spending, expected returns and the overall economy.

More recently research efforts have attempted to meet the criticism that earlier studies of the credit channel failed to isolate supply shocks from demand shocks and persuasively establish the existence of real effects. To avoid identification issues, this later work has tested the cross-section

\footnotetext{
${ }^{2}$ An important indicator of this phenomenon is the bond spread between Baa corporate bonds and Treasury bonds, that increased from 2.5 percent in 1929-30 to nearly 8 percent in mid 1932. See Bernanke (1983) p.266.

3 Bernanke and Gertler (1990) define financial instability ("fragility") as a situation in which potential borrowers have low wealth relative to the sizes of their projects.
} 
implications of the credit view. For example, Gertler and Gilchrist $(1993,1994)$ find that larger firms have better access to credit and typically respond to unexpected adverse conditions by increasing short-term borrowing, while smaller firms instead respond by squeezing inventories and cutting production. Bernanke, Gertler and Gilchrist (1996) obtain similar findings when they split up firms according to their degree of bank dependency rather than based on size. Samolyk (1994) examines the relationship between banking conditions and economic performance at the U.S. states level and finds that local bank balance-sheet conditions help to predict the performance of regional economies in a way that is consistent with the existence of credit market imperfections. Ludvigson (1998) uses automobile credit data from bank and non-bank sources and finds evidence for the presence of a bank lending channel. Peek and Rosengren (2000) study the effects of the Japanese banking crisis on construction activity in the U.S. Their work makes clear that the retrenchment of Japanese lending had a substantial impact on U.S. real estate activity, indicating that at least some borrowers were not able to obtain alternative financing and that credit markets thus were suffering from imperfections. Repullo and Suarez (2000) develop a theoretical model that can compare the macro implications of both the balance-sheet channel and the bank lending channel and conclude that the presence of a balance-sheet channel is most likely.

This paper is closely related to the above work as we study the interaction between real activity and firms' balance sheets. Unlike earlier studies, however, that primarily seek to identify a one-way linkage between the macroeconomy and financial markets, we combine a microeconometric model of firms' financial default behavior and a macroeconometric model to study how macro aggregates and the aggregate effects of changes in individual firms' balance sheets and income statements interact with each other. Our focus is less on the existence of a "credit channel" but rather on the interaction between the economy's financial stance at the firm level and the economy's aggregate behavior. Although our link between micro conditions and the macro model is not derived from micro-foundations, we believe that this eclectic approach offers a number of advantages. For one thing, we will be able to investigate if macroeconomic policy will affect businesses equally, both cross-sectionally and through time. We will also be able to look into the relative importance of firm-specific and aggregate disturbances. ${ }^{4}$

We model the macroeconomy by a set of macroeconomic variables, including the aggregate bankruptcy frequency, in a quarterly vector autoregressive model. Furthermore, the impact of

\footnotetext{
${ }^{4}$ Although we are aware of the importance of job and business creation, our focus here is on interaction between the macroeconomy and business default (destruction).
} 
firms' balance-sheet variables on bankruptcy risk is modeled in a dynamic panel data model, where we also condition on macroeconomic variables. To this end we have collected an extensive data set containing balance-sheet information on the entire population of Swedish incorporated firms (some quarter of a million firms) for 40 consecutive quarters, 1990Q1 - 1999Q2 (in total, close to 8 million firm-observations). This sample period covers the "banking crisis" period in Sweden $(1991$ - 1993) and also a benign period characterized by high growth in the late 1990s.

The empirical model is a system made up of three blocks. The first one is a vector autoregressive (VAR) model for the macroeconomic variables we consider. Based on work by Lindé (2002), we choose to include the following endogenous variables in the VAR; output, inflation, the nominal interest rate (the REPO rate), and the real exchange rate. Since Sweden is a small open economy it is necessary to condition on a set of foreign variables that enters the model exogenously. As another exogenous variable in the VAR we include our preferred measure of the financial stance, the aggregated default frequency of incorporated firms, a variable that is highly positively correlated with the banking sector credit losses during the 1990s. An important first step in the analysis is to use a multivariate Granger-causality test, or block-exogeneity test, to what extent various financial indicator variables are helpful predictors of the macroeconomy. This exercise is undertaken for a larger set of financial variables, and we find that the aggregate default frequency is the most important one.

In the second block we have a logit model for the default risk at the firm level where the macroeconomic variables as well as various balance-sheet variables enter as regressors. The logit model will carefully follow the methods that have been applied in earlier studies on company default, such as Altman and Saunders (1997), Shumway (2001) and Carling, Jacobson, Lindé and Roszbach (2004). Let $D_{i, t}$ denote default status of firm $i$ in period $t$. By computing $\left(\sum_{i} D_{i, t}\right) / N_{t}$, where $N_{t}$ is the number of firms each time period, we retrieve a time-series of the aggregate default frequency that can be inserted into the VAR model. So, once equipped with a VAR model and the estimated logit model, we can simulate the effects of various disturbances in the economy. For instance, we can study the dynamic effects of a shock to monetary policy on inflation and the default frequency in a joint framework.

The third block in the empirical model is an attempt to estimate how the balance-sheet variables that are included in the logit model depend on the macroeconomic variables. Due to the panel-data nature of our firm-level data set, we estimate a dynamic panel VAR-type model for the balance-sheet variables (that are included in the logit model) letting the macro variables enter 
as regressors. We can then study if the macroeconomic variables are quantitatively important for explaining variation in the balance-sheet variables.

Our main findings are as follows. First, we find that the aggregate default frequency is a significantly and quantitatively important link from the financial to the real side of the economy, whereas other commonly considered financial indicators appear less so. Second, we find that macroeconomic variables are important for explaining a time-varying default frequency. Firmspecific variables are very useful in ranking the riskiness of firms, but macroeconomic variables are of crucial importance for explaining changes in absolute default risk. Third, most of the variation in balance-sheet variables are of idiosyncratic origin. Fourth, the empirical model implies that the effects of monetary policy on the default frequency and the inflation rate are state dependent: monetary policy appears to be more potent under recessions than during booms. Finally, we find that our empirical model appears to more accurately produce joint forecasts of inflation and the aggregate default frequency in comparison to a standard VAR model where the default frequency is included as an endogenous variable.

The remainder of this paper is structured as follows. In the next section, we present our micro and macro data sets. The dependency of the real side of the economy on the set of financial variables we study is examined in Section 3. In Section 4, we test for the dependency of the financial variables for the macro variables. In Section 5 , we summarize the empirical models that are used to examine the interaction between the real and financial side of the economy. The empirical micro-macro model is then used in Section 6 to shed light on some interesting policy issues. In this section, we also compare the properties of this model with those of a VAR-model where the aggregate default frequency is included as an endogenous variable. Finally, Section 7 concludes.

\section{Data}

\subsection{Micro data}

In this subsection, we provide a detailed description of our data set at the firm level.

The final data set is a panel consisting of 7,652,609 quarterly observations on incorporated firms, covering ten years of quarterly data for all Swedish aktiebolag companies that have issued a financial statement between January 1, 1990, and June 30, 1999. Aktiebolag are by approximation the Swedish equivalent of US corporations and UK limited businesses. Swedish law 
requires every aktiebolag to have at least SEK 100,000 (approximately US\$10,000) of equity to be eligible for registration at the Swedish Patent and Registration Office (PRV). Firms are also required to submit an annual report to PRV. Small firms such as general partnerships, limited partnerships and sole proprietors will be disregarded, since, as reported by Jacobson and Lindé (2000), incorporated firms by far account for the largest fraction of loans and, also, display the most cyclical variation in default risk.

The firm-data come from Upplysningscentralen AB (UC), a major credit bureau in Sweden, and are from two general sources of information. First, UC has provided us with balance-sheet and income statement data from the firms' annual reports submitted to PRV. These annual report data cover the period January 1, 1989 to December 31, 1999. Second, UC has provided us with historical data on events related to payment remarks and payment behavior for the firms and for their principals. The UC-data are available at different frequencies, varying from daily for payment remarks to (most often) annually for accounting data. We will discuss the specifics of the data in greater detail below.

The accounting data contains information on most standard balance-sheet and income statement variables. Appendix A, which is available upon request, contains a complete list of annual report variables. In addition to the annual report data, we have information on the firms' track records regarding payment behavior as recorded by remarks for 61 different credit and tax related events. The storage and usage of payment remarks are regulated by the Credit Information Act, the Personal Data Act and overseen by the Swedish Data Inspection Board. Examples of events that are registered are: delays in tax payments, the repossession of delivered goods, the seizure of property, the resettlement of loans and actual bankruptcy. In practice, with a record of payment remarks individuals will not be granted any new loans and businesses can find it very difficult to open new lines of credit. Appendix B, which is available upon request, contains the complete list of payment remarks.

We define the population of existing firms in quarter $t$ as the firms which have issued a financial statement covering that quarter and are classified as "active". For a firm to be classified as active, we require that is has total sales and total assets over 1000 SEK (roughly 100\$). In addition to these firms, we add the firms which according to the data set on remarks are classified 
as defaulted firms. ${ }^{5}$ The adopted definition of default is the one used by UC. ${ }^{6}$

In Table 1, we report all descriptive statistics for the employed accounting ratios and other variables, such as payment remarks and average delayed time to the last issued financial report for the defaulted and non-defaulted firms. Because of varying availability of data, the statistics in Table 1 were calculated based on different numbers of observations. For firms where accounting data are not available, we replace missing values by the panel mean for the defaulted/nondefaulted firms. In part A of Table 1, showing non-truncated data, there are some accounting data observations that clearly are severe outliers. These observations would seriously distort the estimation results if they were to be included in the logit model. Therefore, we have truncated the top and bottom 1 percent observations for the accounting variables. ${ }^{7}$ Given the large number of observations, this approach is more or less equivalent to simply deleting 1 percent of the observations that have accounting data that fall outside a certain region. Part B of Table 1 shows the descriptive statistics for the truncated micro data set. ${ }^{8}$

As financial reports issued by firms typically become available with a significant time lag, it cannot in general be assumed that accounting data for year $\tau$ are available during or even at the end of year $\tau$ to forecast default risk in year $\tau+1$. To account for this, we have lagged all accounting data by 4 quarters in the estimations. For most firms, who report balance-sheet and income data over calendar years, this means that data for year $\tau$ is assumed to have been available in the first quarter of year $\tau+1$.

For a number of firms some transformation had to be applied to the accounting variables to adjust for reporting periods that did not coincide with the calendar year, to assure that each variable is measured in identical units for all firms. Some firms, for example, report accounting information referring to three-month or four-month periods for one or several years. In such

\footnotetext{
${ }^{5}$ There is a simple reason why we need to add firms that have defaulted to the population of firms defined by the accounting data. Many firms that default choose not to submit their compulsary annual reports in the year, or even years, prior to default. Hence, the only records of their existence that we have come from the remark registers.

6 According to the UC-definition, a firm has default status if any of the following more important events have occured: the firm is declared bankrupt in the legal sense, it has suspended payments, it has negotiated a composition settlement, it is undergoing a re-construction, or, distraint with no assets. We differ somewhat from the credit bureau's definition though, in that we use a one quarter horizon, whereas they currently employ a one-year horizon.

7 This approach is quite common in the literature, and e.g. Shumway (2001) also truncate 1 percent of the top and bottom observations. It should be emphazied that the results are not at all sensitive when varying the truncation rate between 0.5 and 2 percent.

8 From Table 1, comparison of the descriptive statistics for the untruncated data makes it clear that defaulted firms are unproportionally more affected when truncating all the observations simultaneously. Since the REMARK1, REMARK2, PAYDIV and TTLFS are dummy variables that are unaffected by our truncation procedure, it may lead to underestimation of the importance of the accounting data variables in the default risk model relative to these dummy variables. To check the robustness of our chosen approach, we used an alternative approach where we truncated the healthy and defaulted firms separately. As expected, the estimation results of the default-risk model with this alternative truncation suggested a somewhat larger role for the accounting ratios, but the over-all picture remains the same.
} 
cases, annual balance-sheet figures were calculated as weighted averages of the multiple period values. In other cases companies did report numbers for a 12-month period, but the period did not coincide with the calendar year. The 1995 figures, for example, could refer to the period 1995-04-01 until 1996-03-31. In these cases, such "deviations" were accounted for by adjusting the "four quarter lag" (and thus the date at which the information is assumed to have been available) correspondingly.

Before we decided to restrict our attention to the set of financial ratios that are shown in Table 1, we studied a number of commonly used accounting ratios that were employed in frequently cited articles studying bankruptcy risk and the balance-sheet channel, but the ones reported show the strongest correlation with default risk. ${ }^{9}$ In our empirical model, we employ six accounting ratios: earnings before interest, depreciation, taxes and amortization over total assets (earnings ratio); interest payments over the sum of interest payments and earnings before interest, depreciation, taxes and amortization (interest coverage ratio); total liabilities over total assets and total liabilities over total sales (debt ratios); cash in relation to total liabilities (cash ratio); and inventories over total sales (turnover ratio). ${ }^{10}$ These six ratios were selected following a two-step procedure. First, the univariate relationship between the ratio and default risk was investigated. By visual inspection, ratios that lacked any correlation with default risk were deleted from the set of candidate explanatory variables. Figure 1 illustrates this for the six selected ratios by comparing default rates (solid line) and the cumulative distributions of the variables (dotted line). The default rate for a given observation of a ratio is calculated as an average over the interval of $+/-5000$ adjacent observations in the empirical distribution of the ratio at hand. Given the density of the observations, there is a positive relationship between default risk and the leverage, interest coverage and turnover ratios, while the figure suggests a negative relationship for both the debt and the liquidity ratios. The diagrams in Figure 1 suggest that the relationship between default-risk and the earnings ratio, total liability over total sales ratio and interest costs over the sum of interest costs and earnings are non-linear. For instance, for the interest coverage variable, this relationship is perhaps what one would have expected; low (negative earnings) can turn this ratio highly negative if interest costs are high but earnings are slightly more negative, and this event is naturally associated with an increased default risk.

\footnotetext{
${ }^{9}$ See Altman (1969, 1971, 1973, 1984), Carling et al. (2004), Frydman, Altman and Kao (1985), and Shumway (2001).

${ }^{10}$ It should be noted that the level of debt, in addition to the leverage ratio $\left(\mathrm{TL}_{i, t} / \mathrm{TA}_{i, t}\right)$ for firm $i$ in period $t$, appears to contain predictive power for default risk. We therefore decided to include $\mathrm{TL}_{i, t}$ as separate variable, but scaled it with average total sales in period $t$ to obtain a stationary accounting ratio. So the debt to sales ratio is actually defined as $\mathrm{TL}_{i, t} / \mathrm{TS}_{t}$, where $\mathrm{TS}_{t}$ denotes average total sales in period $t$.
} 
On the other hand, high interest payments and low earnings will also make this ratio large, and is likewise associated with an increased default risk. Similar reasoning can be be applied to the other ratios as well. What is important to note is that this feature for some of the financial ratios does not imply that these variables are uninformative for default risk in the empirical model. The reason for this being that the correlations between these financial ratios in the cross section are substantial, which makes each of these variables contribute to predicting default risk in the joint empirical model. ${ }^{11}$ Taking these insights into account, Figure 1 confirms the picture emerging from Table 1: there is a clear difference between healthy and defaulted firms for these variables.

\footnotetext{
11 For instance, taking the square of the interest coverage ratio, which, judging by Figure 1, would seem appropriate in a single variable analysis, reduces the explanatory power of this variable in the multivariate model.
} 
Table 1: Descriptive statistics for the micro data.

\begin{tabular}{|c|c|c|c|c|c|c|c|c|}
\hline \multicolumn{9}{|c|}{ Part A: Non-truncated data } \\
\hline Firm Type & $N$ & $\mu$ & $\sigma$ & $\begin{array}{c}\text { Statistic } \\
\text { min }\end{array}$ & $1 \%$ & $50 \%$ & $99 \%$ & $\max$ \\
\hline Non-defaulted & 7549041 & & & & & & & \\
\hline EBITDA/TA & 7471212 & -0.12 & 220.40 & -256885 & -1.03 & 0.11 & 0.85 & 66424 \\
\hline $\mathrm{TL} / \mathrm{TA}$ & 7474248 & 3.56 & 1351.21 & -408 & 0.03 & 0.73 & 2.42 & 1703742 \\
\hline $\mathrm{LA} / \mathrm{TL}$ & 7451325 & 1.09 & 109.37 & -71203 & 0 & 0.13 & 7.94 & 54655 \\
\hline $\mathrm{I} / \mathrm{TS}$ & 7355762 & 4.84 & 6254.23 & -26845 & 0 & 0.01 & 2.18 & 16500000 \\
\hline TL/TS & 7474248 & 2.32 & 120.73 & -32.25 & 0 & 0.08 & 17.02 & 48536 \\
\hline $\mathrm{IP} /(\mathrm{IP}+\mathrm{EBITDA})$ & 7457030 & $-1.7 \mathrm{e} 10$ & $2.8 \mathrm{e} 13$ & 0 & -3.59 & 0.10 & 3.95 & $2.2 \mathrm{e} 16$ \\
\hline Defaulted & 103568 & & & & & & & \\
\hline EBITDA/TA & 67093 & -6.04 & 1201.38 & -215719 & -5.40 & 0.03 & 1.23 & 164895 \\
\hline $\mathrm{TL} / \mathrm{TA}$ & 67110 & 208.17 & 25784.42 & -23304 & 0.01 & 0.94 & 18.97 & 5407312 \\
\hline $\mathrm{LA} / \mathrm{TL}$ & 66729 & 0.57 & 24.20 & -436 & 0 & 0.02 & 4.87 & 3258 \\
\hline $\mathrm{I} / \mathrm{TS}$ & 63138 & 27.05 & 6319 & -0.19 & 0 & 0.03 & 5.21 & 1587085 \\
\hline TL/TS & 67110 & 0.80 & 8.46 & -0.08 & 0 & 0.12 & 9.53 & 787 \\
\hline IP /(IP+EBITDA $)$ & 66670 & 0.35 & 28.53 & -1216 & -6.09 & 0.23 & 6.90 & 5794 \\
\hline
\end{tabular}

Part B: Truncated data

\begin{tabular}{|c|c|c|c|c|c|c|c|c|}
\hline Firm type & $N$ & $\mu$ & $\sigma$ & $\begin{array}{l}\text { Statistic } \\
\min \end{array}$ & $1 \%$ & $50 \%$ & $99 \%$ & $\max$ \\
\hline Non-defaulted & 7549041 & & & & & & & \\
\hline EBITDA/TA & 7471212 & 0.11 & 0.25 & -1.05 & -1.03 & 0.11 & 0.84 & 0.84 \\
\hline $\mathrm{TL} / \mathrm{TA}$ & 7474248 & 0.71 & 0.35 & 0.03 & 0.03 & 0.73 & 2.42 & 2.46 \\
\hline $\mathrm{LA} / \mathrm{TL}$ & 7451325 & 0.53 & 1.12 & 0 & 0 & 0.13 & 7.81 & 7.81 \\
\hline $\mathrm{I} / \mathrm{TS}$ & 7355762 & 0.12 & 0.29 & 0 & 0 & 0.01 & 2.13 & 2.13 \\
\hline TL/TS & 7474248 & 0.58 & 2.08 & 0 & 0 & 0.08 & 14.74 & 18.61 \\
\hline $\mathrm{IP} /(\mathrm{IP}+\mathrm{EBITDA})$ & 7457030 & 0.15 & 0.76 & -3.55 & -3.55 & 0.10 & 3.91 & 3.91 \\
\hline PAYDIV (\%) & 7549041 & 13.15 & 33.80 & 0 & & & & 1 \\
\hline REMARK1 (\%) & 7549041 & 0.33 & 5.77 & 0 & & & & 1 \\
\hline REMARK2 (\%) & 7549041 & 3.06 & 17.21 & 0 & & & & 1 \\
\hline TTLFS (\%) & 7549041 & 1.54 & 12.30 & 0 & & & & 1 \\
\hline Defaulted & 103568 & & & & & & & \\
\hline EBITDA/TA & 67093 & -0.03 & 0.35 & -1.05 & -1.05 & 0.03 & 0.84 & 0.84 \\
\hline $\mathrm{TL} / \mathrm{TA}$ & 67110 & 1.00 & 0.50 & 0.03 & 0.03 & 0.94 & 2.46 & 2.46 \\
\hline $\mathrm{LA} / \mathrm{TL}$ & 66729 & 0.21 & 0.82 & 0 & 0 & 0.02 & 4.87 & 7.81 \\
\hline $\mathrm{I} / \mathrm{TS}$ & 63138 & 0.18 & 0.38 & 0 & 0 & 0.03 & 2.13 & 2.13 \\
\hline $\mathrm{TL} / \mathrm{TS}$ & 67110 & 0.57 & 1.75 & 0 & 0 & 0.12 & 9.52 & 18.61 \\
\hline $\mathrm{IP} /(\mathrm{IP}+\mathrm{EBITDA})$ & 66670 & 0.24 & 0.99 & -3.55 & -3.55 & 0.23 & 3.91 & 3.91 \\
\hline PAYDIV (\%) & 103568 & 0.70 & 8.31 & 0 & & & & 1 \\
\hline REMARK1 (\%) & 103568 & 14.90 & 35.61 & 0 & & & & 1 \\
\hline REMARK2 (\%) & 103568 & 40.60 & 49.11 & 0 & & & & 1 \\
\hline TTLFS $(\%)$ & 103568 & 33.42 & 47.17 & 0 & & & & 1 \\
\hline
\end{tabular}

Notes: The definition of variables are: EBITDA = earnings before taxes, interest payments and depreciations; $\mathrm{TA}=$ total assets; $\mathrm{TL}=$ total liabilities; $\mathrm{LA}=$ liquid assets; $\mathrm{I}=$ inventories; $\mathrm{TS}=$ total sales; $\mathrm{IP}=$ sum of net interest payments on debt and extra-ordinary net income; PAYDIV = a dummy variable equal 1 if the firm has paid out dividends during the accounting period and 0 otherwise; REMARK1 = a dummy variable taking the value of 1 if the firm has a payment remark due to one or more of the following events in the preceding four quarters; (i) a "non-performing loan" at a bank, or (ii) a bankruptcy petition, or (iii) issuance of a court order to pay a debt, or (iv) seizure of property; REMARK2 = a dummy variable taking the value of 1 if the firm is in various tax arrears; TTLFS = a dummy variable equal to 1 if the firm has not submitted an annual report in the previous year, and 0 otherwise. 
For the remark variables, we employ the same approach as in Carling et al. (2004) and use simple dummy variables by setting them to unity if certain remarks existed for the firm during the year prior to quarter $t$, and 0 otherwise. An intuitively reasonable starting point was to find remark events that (i) lead default as much as possible and (ii) are highly correlated with default. As it turned out, many remark variables are either contemporaneously correlated with default or lack a significant correlation with default behavior. For our final model, we constructed the REMARK1-variable as a composite dummy of four events: a bankruptcy petition, the issuance of a court order - because of absence during the court hearing - to pay a debt, the seizure of property, and "having a non-performing loan", and the REMARK2-variable reflects if the firm is in various tax arrears. In the accounting data, we also have information whether a firm has paid out dividends or not. We therefore included this information as a dummy variable (PAYDIV) in the model, taking the value of 1 if the firm has paid out dividends and 0 otherwise.

In addition, we have included a dummy variable, denoted TTLFS, which equals unity if a firm has not issued a financial statement one and a half year prior to default, and zero otherwise. ${ }^{12}$ The reason for including this variable in the default-risk model is the notion that firms who are about to default are less willing to report information about their financial status. By comparing defaulting and healthy firms in Table 1 we see that this mechanism is at work in the panel.

\subsection{Macro data}

The macro data used in this paper is adopted from Lindé (2002) and covers the period 1986Q32002Q4. We restrict the sample to this period because Swedish financial markets were heavily regulated prior to 1986. The domestic variables are $y_{t}^{d}$ - the output-gap (i.e., deviation of GDP around its trend value), $\pi_{t^{-}}^{d}$ the annual inflation rate (measured as the fourth difference of the GDP-deflator), $R_{t}^{d}$ - the REPO nominal interest rate (a short-term interest rate, controlled by the Riksbank), and $q_{t}$ - the real exchange rate. ${ }^{13}$ Because there is a strong trend for the real

\footnotetext{
12 There are three things worth noting in connection with the definition of TTLFS. First, this information is assumed to be available with a 6 quarter time lag since financial statements for year $\tau$ are typically available in the third quarter in year $\tau+1$. By letting this dummy variable equal unity with a 6 quarter time lag we do take the real-world time delay into account. Second, given the way we define the population of existing firms, firms that are newly registered and enter into the panel would automatically be assigned TTLFS $=1$ in the third quarter of their existence since they have not issued any financial statement prior to entering. For these new firms, TTLFS has been set to 0 and the accounting data variables have been taken from their first yearly balance sheet and income statements. Third, for defaulting firms that are in the panel but have never reported any accounting data prior to default, we also set TTLFS equal to 0 . This is the case for 38,352 out of 103,568 defaulting firms in the panel. So although TTLFS turns out to be very important in the default-risk model, by construction the importance of this variable is down-played rather than exaggerated.

${ }^{13}$ The real exchange rate is measured as the nominal TCW-weighted ( $\mathrm{TCW}=$ trade competitive weights) exchange rate times the TCW-weighted foreign price level (CPI deflators) divided by the domestic CPI deflator.
} 
exchange rate during the sample period, this variable is detrended as well. ${ }^{14}$ Since Sweden is an open economy, it is important to condition on foreign variables in the VAR-model. Consequently, we also include $y_{t}^{f}$ - the foreign output gap (computed by Lindé, 2002), $\pi_{t}^{f}$ - foreign inflation rate, and $R_{t}^{f}$ - the 3 -month nominal interest rate as exogenous variables. To acquire data on the aggregate default frequency, denoted $d f_{t}$ for the sample outside the panel period $1990 Q 1-$ 1999Q2, we linked the panel series depicted in Figure 2 for 1986Q3 - 1989Q4 with the aggregate default frequency data for all business firms (made available by Statistics Sweden), and for the period 1999Q3 - 2002Q4 with the aggregate default frequency for incorporated firms (again, source Statistics Sweden).

\section{The dependency of real variables on financial variables}

In this section, we use aggregate data to examine if there is a feedback from the financial side to the real side of the economy. Throughout the analysis, we will work with the VAR model estimated by Lindé (2002) as the tool to study this issue. The $\operatorname{VAR}(p)$-model with $p$ lags is specified as

$$
X_{t}=C_{d}+\delta_{1} D_{923}+\delta_{2} D_{931013}+\tau_{d} T_{t}+\sum_{i=0}^{p} F_{i} Z_{t-i}+\sum_{i=1}^{p} B_{d, i} X_{t-i}+u_{d, t},
$$

where $D_{923}$ is a dummy variable equal to 1 in $1992 Q 3$ and 0 otherwise, $D_{931013}$ is a dummy variable equal to 1 in $1993 Q 1$ and thereafter, $T_{t}$ is a linear time-trend, and $Z_{t}$ is a vector with the exogenous variables. The dummy variable for the third quarter in 1992 is included to capture the exceptionally high interest rate increase (up to 500 percent) implemented by the Riksbank in order to defend the fixed Swedish exchange rate. Despite the efforts to defend the Swedish krona, Sweden entered into a floating exchange rate regime in late November 1992, and the dummy variable $D_{931013}$ is included in order to capture possible effects of the new exchange rate regime.

\footnotetext{
${ }^{14}$ Lindé (2002) estimates a VAR with 2 lags for the period 1986Q3 - 2002Q4 and generates a trend for the variables by doing a dynamic simulation of the estimated VAR under the assumption of no shocks hitting the equations. The detrended variables are then computed as actual values minus the trend values. It should be noted, however, that using HP-filtered data for output and the real exchange rate produces very similar results to those reported.
} 
The variables in $X_{t}$ and $Z_{t}$ are

$$
\begin{aligned}
X_{t}= & {\left[\begin{array}{llll}
y_{t}^{d} & \pi_{t}^{d} & R_{t}^{d} & q_{t}
\end{array}\right]^{\prime} } \\
& \text { and } \\
Z_{t}= & {\left[\begin{array}{lll}
y_{t}^{f} & \pi_{t}^{f} & R_{t}^{f}
\end{array}\right]^{\prime} . }
\end{aligned}
$$

Lindé (2002) shows that two lags is sufficient (i.e., we set $p=2$ ), and that the foreign variables are block exogenous with respect to the domestic variables, i.e., the variables in $Z_{t}$ are not affected by the variables in $X_{t}$.

One natural way to test if there is a feedback from the financial sector into the real side of the economy is to augment the specification in (1) with lags of the financial variable, i.e., include $d f_{t-1}$ and $d f_{t-2}$ and examine if they contain useful information for predicting the endogenous variables in the model. This has the flavor of a multivariate Granger-causality test. Essentially, one simultaneously test if the coefficients for the lags are significantly different from zero or not. By using the block-exogeneity test described in detail by Hamilton (1994), cf. pages 309312 , we find that the $p$-value for the null of zero coefficients is around 0.02 , indicating that the macroeconomic variables in $X_{t}$ are not exogenous with respect to the aggregate default frequency.

An alternative way to quantify the dependence of the real economy on the default frequency is to include $d f_{t}$, ordered last, in the $X_{t}$-vector and estimate a five-variable VAR-model. If the impulse response functions in the estimated VAR model for a shock to $d f_{t}$, identified via a so called Cholesky-decomposition, are close to zero, then the quantitative feedback from the default frequency to the real economy is small. In Figure 3, we show the impulse response functions a positive shock to the $d f_{t}$ variable. We see that the outcome of the block-exogeneity test is confirmed, the financial shock has significant effects on the real economy. Output and inflation falls, while the nominal interest rate increases (although not significantly), and the real exchange rate appreciates. According to the VAR, exogenous variations in the default rate account for as much as 20 percent of the variation of the other variables.

We have also investigated whether the average balance sheets ratios (depicted in Figure 4) explain the variation in the macrovariables over and above the explanatory power of the default rate variable and the other macrovariables included in the VAR. Since we only have data on the balance sheets ratios for the period $1990 Q 1-1999 Q 2$, we regressed the VAR-residuals for this period on the balance-sheet ratios equation by equation with OLS. A simple $F$-test revealed that 
the balance-sheet ratios conveyed no information w.r.t. the VAR residuals, the average $p$-value being around 0.60 and the lowest $p$-value 0.25 (real exchange rate residuals). Consequently, we will adopt the approximation in the rest of the paper that the macrovariables included in the VAR above are not directly affected by the balance-sheet ratios that we consider. We will, however, allow for indirect effects via the average default rate.

To complete the analysis, we have also applied the block-exogeneity tests for other commonly used measures of the financial stance of the economy such as the term-structure, the change in the stock of loans by banks to firms and households, the change in stock prices and the change in housing prices. We obtained the following $p$-values; term structure - 0.39 , annual change in stock of outstanding loans - 0.25 , quarterly change in stock prices - 0.90, and quarterly change in housing prices - 0.01 Notice that for the variables in changes, we considered both quarterly and annual changes in respective indicator, but here we only report the results with the lowest $p$-values. These findings suggest that only housing prices contain significant predictive power for the real economy during this sample period. Since stock markets are supposedly forwardlooking, it is perhaps surprising that stock prices appear to contain little predictive power. The reason is simply that there is excessive volatility in stock prices, which is not transmitted into the real economy. Although we find evidence that housing prices are important, the default rate is slightly more important in the sense that if we redo the block exogeneity test for the VAR for housing prices when the default rate is included, we find that the $p$-value being 0.13 . The converse experiment, i.e., testing for the predictive power of the average default frequency given that the first difference of the housing prices are included in the VAR, we obtain a $p$-value of 0.09. Based on the evidence above, and since we are in disposal of very interesting micro data on firms default behavior, we will work with this variable as the link between the financial and real side of the economy, but future research should further address the link between the housing prices and the real economy.

Despite our encouraging statistical evidence in favor of our choice of using the average default frequency for incorporated firms as a link between the real and financial side of the economy, we still need to motivate from an economic perspective why the aggregate default rate is an appropriate measure of the financial stance of the economy. There are several arguments why we think this is the case. First, as shown in Figure 5, we see that the average (aggregate) default frequency displays a very similar pattern to credit-losses over the stock of loans to non-financial 
firms, the correlation coefficient being $0.90 .{ }^{15}$ In particular, the co-movement of the variables is large at the lower frequencies, but there are some differences at the higher frequencies, e.g. the upturn of credit losses during the Asian and Russian crisis. In our view, the lower frequency component of these variables are most interesting, since they are arguably more related to the systematic risks in the banking sector. Second, neither credit-losses, nor defaults, are leading or lagging the other variable. Third, Figure 5 suggests that our choice of restricting the analysis to default risk and not studying implied credit-losses (e.g. by using total liabilities) due to lack of accounting data for many defaulted firms, does not seem to be a serious restrictive approximation. Fourth, from a financial stability perspective, we think that this variable should be of high relevance given that it is forecastable, whereas e.g. operational risks are much harder to forecast. For instance, it would have been extremely difficult for a central bank to foresee the Barings bank affair. Fifth, and finally, we think that our variable ought to capture the leverage/systematic risk in the banking system in the sense that when a bank experiences high default-/credit-risk, it is most likely that other banks will too if there are common factors that drive default risk (e.g. if macroeconomic factors are important for the absolute level of defaultrisk, which is what we find). Thus we conclude that our variable ought to be a good operational predictor of the systematic risk in the banking sector and the financial stance of the economy.

The conclusions from the analysis above are that, (i), there seems to be an important link from the financial side of the economy to the real side of the economy which is not only statistically, but also quantitatively important, and (ii), that the aggregate default rate is a good measure of the financial stance of the economy.

\section{The dependency of financial variables on aggregate activity}

In this section, we examine if default risk at the firm level is affected by aggregate shocks over and above firm-specific information. Moreover, we will present some brief evidence of the balance-sheet channel by investigating to what extent standard balance-sheet ratios are affected by aggregate shocks.

\footnotetext{
${ }^{15}$ Credit losses are here defined as the credit losses to non-financial firms incurred by the four major banks in Sweden (SEB, Nordea, SwedeBank and SHB) in relation to their stocks of loans to non-financial firms.
} 


\subsection{The default-risk model}

In this subsection we present a reduced form statistical model for estimation of probability of default for all Swedish incorporated firms. The general idea is to enter factors that determine the probability of default and quantify how these contribute towards predicting default realizations. With such estimated probabilities we may proceed to calculate the expected aggregate default frequency over time.

So far relatively few empirical studies contain a rigorous analysis of the effects from macroeconomic conditions on default behavior and credit risks at the firm level, see e.g. Carling et al. (2004) for a discussion. The logit model of the default probability that we present in this subsection includes both idiosyncratic and macroeconomic explanatory variables. ${ }^{16}$ The reason for including aggregate variables in the model is clear by inspection of Figures 4 and 5. In Figure 4 , we plot the mean values of the idiosyncratic financial variables that are used in the model $1990 Q 1-1999 Q 2$. It is obvious that there are no dramatic changes in the variables during the deep recession 1992-1993. Therefore, a model with only idiosyncratic variables included is unlikely to fully account for the higher default frequency outcomes at the aggregate level depicted in Figure 2. Therefore, we conjecture that it is important to use aggregate variables in the model.

The macroeconomic variables that we use in the model are the same as included in the domestic VAR model given by (1), i.e., the output gap, the domestic annual inflation rate, the REPO rate, and the real exchange rate. A priori, we think that these should have a measurable impact on the default risk of any given firm. Starting with the output gap, it may supposedly work as an indicator of demand conditions, i.e. increased demand in the economy reducing default risk. Figure 5 seems, at large, consistent with this view, although there are some spikes in the default rate that presumable have to be attributed to other variables. Also, it is clear from Figure 2 that there has been some variation the output gap around 1996-1998 which has not been met with an increased default rate. Therefore, there must be some other aggregate variables that ought to be important as well. Here, we decided to include the nominal interest rate (i.e. the REPO rate) because we know that the nominal interest rate was very high during the recession in the beginning of the 1990s, but has came down substantially after

\footnotetext{
${ }^{16}$ For simplicity, we estimate a logit-model rather than a duration model as is done in Carling et al. (2004). Although Carling et al., in contrast with Shumway (2001), found significant evidence of a duration dependence, we believe that this approximation may not be of decisive importance. But an interesting extension of this work is to test for duration dependence in the model.
} 
the introduction of the inflation target in Sweden. Given the fact that the export to GDP ratio being around 0.40 , the real exchange rate is also a potentially important variable, a deprecation leading to improved competitiveness of Swedish firms. The inflation rate may also be important for firms pricing decisions; higher inflation rates are potentially associated with less certainty about correct relative prices, and may thus lead to potentially higher default risk. Of course, it also convenient to work with variables that can be generated from the VAR-model in the previous section. This is the reason why we did not experiment with neither a term structure variable, nor measures of household expectations as in Carling et al. (2004). Finally, as can be seen from Figure 2, there is a large spike in the REPO rate in the third quarter 1992 due to the fact that the Riksbank raised the so called marginal interest rate to 500 percent in order to defend the fixed exchange rate. If the REPO rate is not adjusted for this exceptional event, the estimation procedure leads to underestimation of the importance of financial costs for default behavior. We therefore decided to adjust the REPO rate series in the third quarter of $1992 .{ }^{17}$

In order to highlight how various variables contribute to default risk, we present three models in Table 2. One model with accounting ratios only, a second augmented with the dummy variables (PAYDIV, REMARK and TTLFS variables), and finally one with the macroeconomic variables added. ${ }^{18}$

\footnotetext{
17 The estimated dummy coefficient in the VAR equals 28.2 in the REPO rate equation. On the basis of this, we adjusted the REPO rate for this quarter to equal 9.8 percent instead of 38 percent.

18 Since no data on the payment records of firms (i.e., the dummy variables REMARK1 and REMARK2) exist prior to $1992 Q 3$ for legal storage reasons, the estimation results of Model II and Model III reported in Table 2 also includes one additional variable (not reported) which is constructed to be an estimate of the average value of the sum of the payment record variables REMARK1 and REMARK2 for the quarters $1990 Q 1-1992 Q 2$. This variable was constructed by estimating a logit model for the event of either of the dummy variables REMARK1 and REMARK2 taking on the value 0 or 1 for the period 1992Q3-1999Q2, using all the variables in Model III (except REMARK1 and REMARK2 as explanatory variables, of course). The imputed average value for this variable for the period 1990Q1-1992Q2 (after 1992Q2, it is set to nil) was then constructed as the average estimated probability for each firm and period, i.e., $\mathrm{RD}_{t}=\frac{1}{N_{t}} \sum_{i} \hat{p}_{i, t}$ where $\hat{p}_{i, t}$ denotes the estimated probability for firm $i$ in period $t$ to have either a REMARK1 or a REMARK2 greater than zero, and $N_{t}$ denotes the number of firms in period $t$. The largest gain in including this variable is that the effects of the macroeconomic variables are more accurately estimated. For the coefficients of the idiosyncratic variables this variable is of little importance.
} 
Table 2: Logit estimation results of the default-risk model. ${ }^{a}$

\begin{tabular}{|c|c|c|c|c|c|c|}
\hline \multirow[b]{2}{*}{ Type of regressor } & \multicolumn{2}{|c|}{ Model I } & \multicolumn{2}{|c|}{ Model II } & \multicolumn{2}{|c|}{ Model III } \\
\hline & Coefficient & Std error & Coefficient & Std error & Coefficient & Std error \\
\hline Constant & -4.76 & 0.018 & -5.22 & 0.025 & -5.88 & 0.059 \\
\hline \multicolumn{7}{|l|}{ Idiosyncratic variables $^{b}$} \\
\hline EBITDA/TA & -1.07 & 0.022 & -1.10 & 0.028 & -1.09 & 0.046 \\
\hline $\mathrm{TL} / \mathrm{TA}$ & 1.07 & 0.015 & 0.54 & 0.020 & 0.52 & 0.0233 \\
\hline $\mathrm{LA} / \mathrm{TL}$ & -0.10 & 0.014 & -0.15 & 0.017 & -0.16 & 0.028 \\
\hline $\mathrm{I} / \mathrm{TS}$ & 0.27 & 0.016 & 0.20 & 0.021 & 0.21 & 0.034 \\
\hline TL/TS & 0.19 & 0.004 & 0.23 & 0.005 & 0.22 & 0.007 \\
\hline IP /(IP+EBITDA $)$ & 0.09 & 0.007 & 0.07 & 0.009 & 0.08 & 0.015 \\
\hline PAYDIV & & & -1.91 & 0.080 & -1.85 & 0.138 \\
\hline REMARK1 & & & 1.73 & 0.032 & 1.89 & 0.051 \\
\hline REMARK2 & & & 2.66 & 0.020 & 2.74 & 0.033 \\
\hline TTLFS & & & 3.32 & 0.019 & 3.27 & 0.031 \\
\hline \multicolumn{7}{|l|}{ Aggregate variables $^{c}$} \\
\hline Output gap - $y_{d, t}$ & & & & & -0.110 & 0.008 \\
\hline Inflation rate $-\pi_{d, t}$ & & & & & -0.005 & 0.009 \\
\hline Nominal interest rate $-R_{d, t}$ & & & & & 0.072 & 0.006 \\
\hline Real exchange rate $-q_{t}$ & & & & & -0.006 & 0.002 \\
\hline \multicolumn{7}{|l|}{ Summary statistics $^{d}$} \\
\hline Mean log-likelihood & \multicolumn{2}{|c|}{-0.0669} & \multicolumn{2}{|c|}{-0.0491} & \multicolumn{2}{|c|}{-0.0484} \\
\hline Pseudo $R^{2}$ & \multicolumn{2}{|c|}{0.16} & \multicolumn{2}{|c|}{0.37} & \multicolumn{2}{|c|}{0.39} \\
\hline Aggregate $R^{2}$ & \multirow{2}{*}{\multicolumn{2}{|c|}{$\begin{array}{l}0.26 \\
2066206\end{array}$}} & \multicolumn{2}{|c|}{0.36} & \multicolumn{2}{|c|}{0.94} \\
\hline Number of observations & & & \multicolumn{2}{|c|}{$1,607,049$} & \multicolumn{2}{|c|}{$765,263^{a}$} \\
\hline
\end{tabular}

Notes: ${ }^{a}$ Since we have as many as 7,652,609 quarterly observations, the computer program used to do the Maximum Likelihood estimation of the logit model (GAUSS version 3.5) cannot handle all observations simultaneously. For Model I and II presented below, we therefore made a random selection of 27 and 21 percent of the observations such that the aggregate default frequency over time is identical to the one computed using all observations. To check for convergence in parameter values, we decreased the estimation samples to 26 and 20 percent of the observations and re-estimated the models. Fortunately, we found convergence in parameter at the three digit level and the estimation results in Table 2 are thus based on the $27 / 21$ percent sized samples, respectively. For Model III this approach was not feasible because we could not find convergence at the three digit level given the increased number of regressors. For this model, we therefore drew 50 samples of size 10 percent of the population, and for each parameter we report the mean estimate of the resulting 50 sub-sample estimates. The standard errors are based on the mean inverse Hessian matrix. ${ }^{b}$ See Subsection 2.1 for exact definition of these variables. ${ }^{c}$ See Subsection 2.2 for definition and sources. The variables are not scaled so the importance of a variable cannot be interpreted directly from the size of the parameter estimate. ${ }^{d}$ We use Laitila (1993) measure of pseudo $R^{2}$. The aggregate $R^{2}$ is computed using all 7,652,609 quarterly observations.

The results in Table 2 show that both idiosyncratic and aggregate information is important for explaining default behavior. The variables for omitted (non-reported) financial statements and remarks on firms payment record are the strongest determinants of default in the model. A nice feature of the estimations is that the coefficients for each variable does not change substantially when the model is augmented with more variables. In particular, the accounting ratios in Model I yield roughly the same coefficients as in the complete Model III. The predictive 
power of the accounting data is somewhat less important than the dummy variables, although the liability-to-assets ratios (TL/TA and TL/TS) and earnings ratios are quite useful. ${ }^{19}$ The turnover ratio for inventories, liquid asset over total liabilities and the interest coverage ratio appear to be less important. Turning to the macroeconomic variables, we find that they are significant, with the exception of inflation, and have the correct signs. Note that a higher value of the real exchange rate implies a depreciation, and therefore the negative estimate for this variable suggests that a depreciation on average reduces the risk of default at a given point in time. It should be pointed out that the macroeconomic variables are highly significant and quantitatively important even if we allow for non-linear effects of the balance-sheet variables. ${ }^{20}$

The advantage of using firm-specific data when estimating the default-risk model can be understood as follows. If we estimate Model III without the dummy variables (REMARK1, REMARK2, PAYDIV, and TTLFS are left out because they do not enter significantly) on aggregate/average data using OLS (TSLS give very similar results), we obtain

$$
\begin{aligned}
& d f_{t}= \underset{(0.06)}{-0.23} \underset{(0.13)}{-0.23}\left(\frac{\mathrm{EBITDA}}{\mathrm{TA}}\right)_{t}+\underset{(0.06)}{0.30}\left(\frac{\mathrm{TL}}{\mathrm{TA}}\right)_{t}+\underset{(0.03)}{0.09}\left(\frac{\mathrm{LA}}{\mathrm{TL}}\right)_{t} \ldots \\
& \underset{(0.21)}{-0.94}\left(\frac{\mathrm{I}}{\mathrm{TS}}\right)_{t}+\underset{(0.08)}{0.19}\left(\frac{\mathrm{TL}}{\mathrm{TS}}\right)_{t}-\underset{(0.12)}{0.02}\left(\frac{\mathrm{IP}}{\mathrm{IP}+\mathrm{EBITDA}}\right)_{t} \ldots \\
& \underset{(0.03)}{0.05} y_{d, t}-\underset{(0.03)}{0.05} \pi_{d, t}+\underset{(0.03)}{0.12} R_{d, t}+\underset{(0.009)}{0.002} q_{t}+\hat{u}_{d f, t}, \\
& R^{2}=0.93, \mathrm{DW}=2.10, \text { Sample: } 1990 Q 1-1999 Q 2(T=38)
\end{aligned}
$$

If we compare the point estimates in Table 2 with those in (3), we see that they differ substantially. In particular, the balance-sheet variables I/TS and LA/TL account for a lot of the variation in the aggregate default rate, but with the wrong sign. Because the accounting ratios are relatively smooth in the aggregate, which is clear from Figure 4, it is not surprising that we

\footnotetext{
${ }^{19}$ Regarding the importance of the accounting data in the model, we would like to emphasize the following features. First, firms typically issue annual financial statements, which we transform into quarterly observations by assuming that they remain the same throughout the reporting period. Given that we define a default event at the quarterly frequency, this assumption could presumably lead to underestimation of the importance of the balance sheet variables in the default risk model. We examined this by estimating the credit risk model at the annual frequency instead, and the coefficients for the balance sheets variables were found to be quite similar. In fact, only the coefficients for EBITDA/TA and TL/TS were found to be slightly higher $(-1.2945 / 0.2652$ instead of $-1.0635 / 0.1768$, respectively), whereas the other coefficients were actually found to be smaller in the annual model. Moreover, the decision to lag the accounting data 4 quarters in the estimation in order to make the model "operationable" in real-time could presumably also affects the estimated coefficients. Therefore, we re-estimated the model using contemporaneous data instead, and again, the estimation results were to found to be very similar.

${ }^{20}$ When estimating the model where the balance-sheet variables enter in a non-linear way (interaction dummies), we used the cumulated distributions depicted in Figure 1 to categorize the balance-sheet variables (3 categories for each variable). For instance, we classified EBITDA/TA into the decile-based categories $0-10,10-90,90-100$, whereas TL/TA was classified into the categories $0-75,75-90,90-100$. The pseudo $R^{2}$ in a non-linear version of Model II is around 0.48 , but the aggregate $R^{2}$ is still slightly below 0.45 . So although this model somewhat better account for the aggregate default frequency, macroeconomic variables are still found to be essential for explaining the absolute level of default risk.
} 
obtain spurious results when estimating the model on aggregate data rather than at the firm level.

In Figures 6 and 7, we plot the aggregate default rate together with the average predicted default rates from Model I (Figure 6) and Model III (Figure 7) for the whole sample of firms, i.e., using the 7,652,609 observations. Very interestingly and as conjectured previously in the paper, we note in Figure 6 that the model with firm-specific information only cannot capture the upand downturns in average default rate over time, whereas the model with both micro and macro variables included is indeed able to replicate the high default rate during the banking crisis, as well as the downturn to very moderate default rates during the latter part of the sample. The explained fraction of variation $\left(R^{2}\right)$ in the model with macro variables included is 94 percent at the aggregate level, whereas it is as low as 26 percent in the model with balance-sheet ratios only. ${ }^{21}$ This finding is very interesting for several reasons. First, because it suggests that the high default rates recorded during the banking crisis were not exceptional events that we cannot learn anything useful from, but rather that they were consequences of unusually bad economic outcomes, both domestically and internationally. ${ }^{22}$ Second, when the aggregate default rate is included in the VAR-model in equation (1) as an endogenous variable, the share of the explained variation in the default rate is about 88 percent and the sum of the two lags for the average default rate is as high as 0.74 . Without the lags, the share of the explained variation in the average default rate shrinks considerably to about 82 percent. ${ }^{23}$ One possible interpretation of these results is that the estimated high weight on the lags in the aggregate default rate equation are proxies for missing information at the firm level, since Model III is estimated at the microeconomic level and gives a better fit at the aggregate level without any intrinsic dynamics in the model.

Finally, one way of demonstrating how much is lost by omitting the micro structure is to regress the average default frequency on the macroeconomic variables included in Model III only.

\footnotetext{
21 The 95 percent confidence intervals around the fitted values in Figure 6/7 cover the actual values 3/15 number of times out of the 38 periods. Thus, while Model III outperforms model Model I in this respect, it seems as though uncertainty around some of the peaks and throughs is underestimated by the bootstrap procedure that we employ and further development is required here. Our single-bootstrap approach for constructing these confidence intervals (bootstrapping parameters in the logit models using a Cholesky-decomposition of the inverse Hessian) seem to result in underestimation of the confidence intervals. Presumably, by adopting a double-bootstrap procedure one can account for the uncertainty in estimated standard errors and achieve reasonable coverage for the confidence intervals. However, a double-bootstrap is currently not feasible in practice.

${ }_{22}$ Lindé (2002) shows that a significant portion of the variation in the domestic macroeconomic variables are of foreign origin.

${ }_{23}$ Note that the numbers for the aggregate default rate are taken from the VAR estimated on a slightly different data sample, 1986Q3 - 2002Q4. However, when restricting the sample to the same period as used for the default-risk model above, the results are actually even more in favor of the micro model.
} 
We then obtain,

$$
\begin{gathered}
d f_{t}=\underset{(0.11)}{1.00}-\underset{(0.03)}{0.19} y_{d, t}+\underset{(0.02)}{0.04} \pi_{d, t}+\underset{(0.01)}{0.02} R_{d, t}-\underset{(0.007)}{0.002} q_{t}+\hat{u}_{d f, t}, \\
R^{2}=0.65, \mathrm{DW}=1.27, \text { Sample: } 1990 Q 1-1999 Q 2(T=38)
\end{gathered}
$$

If we compare the results of this regression with the results in Table 2, we see that we loose about 30 percent of the explanatory power by excluding the balance-sheet variables. This number is in line with the aggregate $R^{2}$ reported in Table 2 for Model I and II.

\subsection{The dependency of balance-sheet ratios on aggregate shocks}

An interesting question is to what extent the balance-sheet ratios are driven by macroeconomic factors and to what extent they live their own lives, i.e., driven by idiosyncratic shocks. There are good reasons to believe that some of the balance-sheet ratios may be more independent of the aggregate state of the economy than others. Consider for example the variable earnings over total assets (EBITDA/TA). In a favorable macroeconomic situation, earnings should improve, as will total assets. Therefore, the net effect on EBITDA/TA is not obvious. However, the coverage ratio $\left(\frac{\mathrm{IP}}{\mathrm{IP}+\mathrm{EBITDA}}\right)$, is likely to be more heavily affected by aggregate shocks, because interest payments on debt (IP) should increase after an increase in the nominal interest rate, while earnings (EBITDA) should fall.

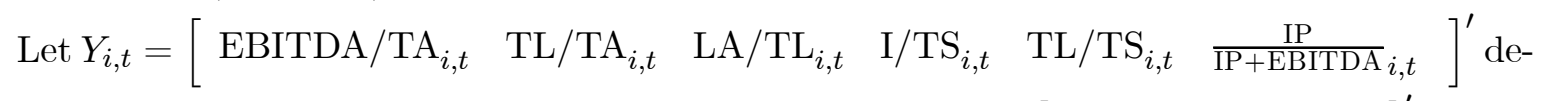

note a $6 \times 1$ vector with the financial ratios for firm $i$, and let $Y_{t}=\left[\begin{array}{llll}Y_{1, t} & . & . & Y_{N_{t}, t}\end{array}\right]^{\prime}$ denote a $6 \times N_{t}$ matrix where $N_{t}$ is the number of firms in the panel in quarter $t$. Then the process for the financial ratios can be written

$$
Y_{t}=\Theta_{Y} Y_{t-1}+\Theta_{X} X_{t}+u_{t}, \operatorname{var}\left(u_{Y, t}\right)=\Sigma_{u}
$$

where $X_{t}$ is defined by (2). Because we want to estimate the model on quarterly data in order to better identify the aggregate shocks, but typically have new information about the financial ratios annually, we use annual moving averages when estimating (5). Each equation in (5) is estimated using the Arrellano and Bond (1991) estimator using 1,701, 878 observations that are constructed from the original data set of all 7,652,609 observations. ${ }^{24}$ The estimation results of (5) are

\footnotetext{
${ }^{24}$ Suppose the true model is given by (5). If we define the variables $\bar{Y}_{t}=\frac{1}{4}\left(Y_{t}+Y_{t-1}+Y_{t-2}+Y_{t-3}\right)$ and $\bar{X}_{t}=\frac{1}{4}\left(X_{t}+X_{t-1}+X_{t-2}+X_{t-3}\right)$, we can write (using 5),

$$
\bar{Y}_{t}=\Theta_{Y} \bar{Y}_{t-1}+\Theta_{X} \bar{X}_{t}+\bar{u}_{t}
$$




$$
\begin{aligned}
& \Theta_{Y}=\left[\begin{array}{rrrrrr}
0.807 & 0.025 & -0.0002 & -0.029 & -0.0003 & -0.006 \\
-0.016 & 0.968 & -0.002 & 0.005 & -0.001 & 0.007 \\
0.007 & -0.062 & 0.938 & -0.011 & -0.0091 & -0.021 \\
-0.004 & -0.001 & -0.0005 & 0.940 & 0.0001 & 0.002 \\
-0.0007 & -0.033 & 0.005 & -0.005 & 0.990 & 0.008 \\
-0.031 & 0.069 & -0.005 & 0.034 & 0.006 & 0.573
\end{array}\right] \\
& \Theta_{X}=100 *\left[\begin{array}{rrrr}
-0.039 & 0.060 & -0.010 & 0.031 \\
-0.026 & 0.016 & 0.053 & 0.004 \\
0.187 & 0.180 & -0.089 & -0.048 \\
0.033 & 0.007 & 0.039 & -0.008 \\
-0.524 & -0.092 & 0.154 & 0.088 \\
-0.167 & -0.007 & 0.148 & -0.021
\end{array}\right] \\
& \Sigma_{Y}=\left[\begin{array}{rrrrrr}
0.15390 & 0.02288 & -0.22309 & 0.04976 & 0.23547 & 0.37508 \\
0.02288 & 0.03079 & -0.10535 & 0.01890 & 0.12979 & 0.14406 \\
-0.22309 & -0.10535 & 1.35270 & -0.18691 & -1.04964 & -1.45223 \\
0.04976 & 0.01890 & -0.18691 & 0.07183 & 0.20798 & 0.31972 \\
0.23547 & 0.12979 & -1.04964 & 0.20798 & 1.24893 & 1.60151 \\
0.37508 & 0.14406 & -1.45223 & 0.31972 & 1.60151 & 2.78039
\end{array}\right] \text {. }
\end{aligned}
$$

We see that there is considerable persistence in the variables, which is presumably due to the fact that we do not allow for firm or industry specific effects when estimating the model. The macro parameters are seemingly small, but the $p$-values for joint Wald-test of all the macro variables are essentially zero in all the equations. However, given that large number of observations, this might not come as a big surprise. Arguably more interesting is to examine to what extent aggregate shocks account for variation in the financial ratios according to the estimates. We found that the macro variables account for maximum 0.1 percent of the fluctuations in the financial ratios included in $Y_{t}$, which implies that the accounting ratios are essentially are living lives of their own. ${ }^{25}$ By looking at Figure 4, these results are not that surprising given that

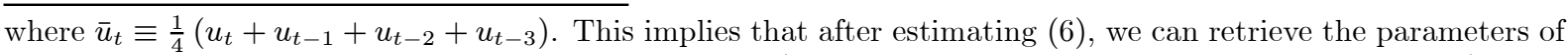
interest $\Theta_{Y}, \Theta_{X}$ and $\Sigma_{u}=4 \Sigma_{\bar{u}}$. As valid instruments (i.e., instruments uncorrelated with the shocks $\bar{u}_{t}$ ) when estimating (6), we use $\bar{Y}_{t-5}$ and $\bar{X}_{t-4}$, thus allowing for one-period, serially correlated measurement errors in $Y_{t}$. This procedure implies that in order for a firm to be included in the estimation, it must have reported a financial statement for 9 consecutive quarters (3 years). This is why the sample used to estimate (6) is considerably smaller than the total number of observations.

${ }_{25}$ Assuming that the unconditional variance in $X_{t}$ is unaffected by the variables in $Y_{t}$ in the long-run, which is a reasonable approximation for reasons discussed in Section 3, we can compute the contribution of the macro variables to fluctuations in $Y_{t}$ as follows. Noting that (5) implies that $\Sigma_{Y}=\Theta_{Y} \Sigma_{Y} \Theta_{Y}^{\prime}+\Theta_{X} \Sigma_{X} \Theta_{X}^{\prime}+\Sigma_{u}$ where $\Sigma_{Y}$, $\Sigma_{X}$ and $\Sigma_{u}$ are the unconditional covariance matrices for $Y_{t}, X_{t}$ and $u_{t}$, respectively. Since the VAR is stable, $\Sigma_{X}$ and $\Sigma_{u}$ known $\left(\Sigma_{X}\right.$ is computed as the covariance matrix for the domestic macro variables $1986 Q 3-2002 Q 4$ and an estimate of $\Sigma_{u}$ is computed from the residuals in (5), we can compute $\Sigma_{Y}$ by iterating on this equation, starting with an arbitrary positive definite matrix as an initial guess. Let $\Sigma_{Y}^{\text {tot }}$ denote the resulting covariance matrix. The amount of variation due to the idiosyncratic shocks can be found by iterating on $\Sigma_{Y}=\Theta_{Y} \Sigma_{Y} \Theta_{Y}^{\prime}+\Sigma_{u}$, and we let $\Sigma_{Y}^{m i c}$ denote the resulting covariance matrix. Similarly, the amount of variation in $Y_{t}$ due to aggregate shocks are found by iterating on $\Sigma_{Y}=\Theta_{Y} \Sigma_{Y} \Theta_{Y}^{\prime}+\Theta_{X} \Sigma_{X} \Theta_{X}^{\prime}$, and we let $\Sigma_{Y}^{m a c}$ denote the resulting covariance matrix. We can then compute the share of fluctuations in the balance sheet ratios due to aggregate shocks as $\operatorname{diag}\left(\Sigma_{Y}^{m a c} \cdot / \Sigma_{Y}^{t o t}\right)$. Notice that $\Sigma_{Y}^{m a c}+\Sigma_{Y}^{m i c}=\Sigma_{Y}^{t o t}$. 
the balance-sheet ratios do not display a strong degree of cyclical behavior, with the possible exceptions of EBITDA/TA and IP/(IP+EBITDA).

Because the effects of the aggregate shocks were found to be surprisingly low, we also conducted the following experiment. For each balance-sheet ratio, we ran simple OLS regressions

$$
Y_{i, t}=c+\sum_{s=0}^{p} b_{s} X_{t-p}+\varepsilon_{i, t}
$$

using both quarterly (setting $p=4$ ) and annual data (using $p=0$ ). From the OLS results, the share of explained variation in $Y_{i, t}$ due to aggregate shocks is directly given by the $R^{2}$ for regression $i$. In none of the estimated equations, we obtained an $R^{2}$ larger than 0.03 , again suggesting a very minor role for aggregate shocks in explaining the fluctuations in firms balancesheet ratios.

However, before drawing too strong conclusions upon these estimation results. The following aspects should be considered. First, the adopted estimation procedure does not allow for firm specific effects, i.e., there is a common intercept in (5) for all firms. However, when we reestimated allowing for firm-specific effects by including a firm-specific constant, we found the importance of the aggregate shocks to be at most 1.9 percent (EBITDA/TA), i.e., very similar to the previous results. But surely, the way one models the firm-specific effects can be of importance for the results. Second, the model is linear, and of course non-linear effects can be of important. Third, and perhaps most important, is that we do not allow for different propagation of aggregate shocks in different industries, since we do not have access to a consistent industry classification over time for all firms (industry classification was changed in 1992). But it seems unlikely that the basic message conveyed, namely that idiosyncratic risk is far more important than aggregate shocks, could be overturned.

\section{Putting all things together: A simple empirical model of the interaction between the real and the financial economy}

In this section, we will briefly describe a simple, but complete model that can be used to study the interaction between the real and financial side of the economy. The model consists of three blocks.

First, we have the VAR-models for the domestic and foreign variables that are estimated on aggregate data. The domestic $\operatorname{VAR}(2)$-model is given by (1) with the terms $\sum_{s=1}^{2} \Lambda_{s} d f_{t-s}$ 
added. In order to be able to study the dependency of the foreign variables, we follow Lindé (2002) and estimate the following $\operatorname{VAR}(2)$-model for the foreign variables

$$
Z_{t}=C_{f}+\tau_{f} T_{t}+\sum_{i=1}^{2} B_{f, i} Z_{t-i}+u_{f, t} .
$$

The second block of the model is the default-risk model (Model III in Table 2). This model is used to compute the average default frequency that enters into the estimated VAR model for the domestic variables, i.e. $d f_{t}=\frac{1}{N_{t}} \sum_{i=1}^{N_{t}} \hat{p}_{i, t}$ where $\hat{p}_{i, t}$ is the estimated default probability for firm $i$ in period $t$ and $N_{t}$ is the number of firms in the panel in period $t$. The third block of the empirical model is the panel VAR-model (5) for the financial ratios which enter into the default-risk model. The default-risk model is the crucial link between the "financial" and "real" side of the economy in this empirical model.

\section{Policy experiments with the empirical model}

In this section, we will discuss how the empirical model can be used to shed light on various policy issues. We will show why we think it is useful for policy makers to use micro information rather than just aggregated data on default risk. That is, we will examine why we think it is better to include the estimated default-risk model in the empirical model rather than making aggregate default frequency an endogenous variable in the VAR-model given by (1). We will also study how the trade-off regarding stabilizing inflation and the aggregate default rate with monetary policy has changed over time in the estimated empirical model. Finally, we will show how one can use the estimated model to compute model consistent joint forecasts for default-frequency and inflation along with uncertainty bands.

\subsection{Computing default frequency distribution percentiles with the model $1991 Q 1$ and $1998 Q 1$}

In this sub-section, we report the results of computing default frequency distribution percentiles with the estimated empirical model. As initial conditions, we take the portfolio compositions as they were in $1991 Q 1$ and 1998Q1, respectively, along with corresponding macroeconomic stances. Note that computing a default frequency distribution is the same thing as computing a loss distribution under the assumption that all loans are of the same size. Computing the default frequency distribution is done in the following way. First we compute a "trend path" 
by simulating the economy when no shocks hit the economy, i.e., $u_{t}^{d}, u_{t}^{f}$ and $u_{i, t}^{y}$ are all zero and using the actual values on the macro variables $\{1990 Q 4,1991 Q 1\}$ and $\{1997 Q 4,1998 Q 1\}$ as starting values (two lags are used in the VARs). Let $d_{t+h}^{\text {trend }}$ denote the computed trend default rate at horizon $h=1,2, \ldots, 8$. Second, we make an additional simulation using the same initial conditions but this time we allow for shocks hitting the economy (i.e., $u_{t}^{d}, u_{t}^{f}$ and $u_{i, t}^{y}$ are now non-zero). Let $d_{t+h}^{\text {shock }}$ denote the outcome when the shocks are included in the model. Third, we compute $d_{t+h}^{D f d}=d_{t+h}^{\text {shock }}-d_{t+h}^{\text {trend }}$, where $D f d$ is spelled out as Default frequency distribution. Fourth, we generate 1,000 realizations of $d_{t+h}^{D f d}$ and choose the upper $(1-X X / 100)$ th percentile for each horizon $h$ of the simulated distribution as our Value-at-Risk-measure of the portfolio of firms in the Swedish corporate sector. We also report the $(1-X X / 100)$ th percentile of the distribution for $d_{t+h}^{s h o c k}$, to ensure that the model is consistent with the fact that default risks were higher in the beginning of the 1990s than during the boom in late 1990s. ${ }^{26}$

In Table 3, we show the resulting figures for the $1991 Q 1$ portfolio and 1998Q1 portfolio of firms. In the table, the absolute default frequency distribution percentile refers to the

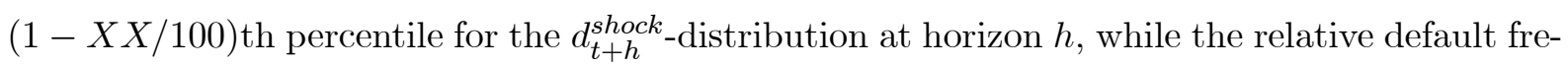
quency distribution percentile refers to the $(1-X X / 100)$ th percentile for the $d_{t+h}^{D f d}$-distribution at horizon $h$. It is important to note that using an aggregate approach, i.e., including the aggregate default frequency as an endogenous variable in the VAR-model, would give rise to exactly the same outcome for the $(1-X X / 100)$ th percentile for the $d_{t+h}^{D f d}$-distribution at horizon $h$ (since the VAR-model is linear). So if these number are different, then this constitutes evidence that the non-linearities induced by the default-risk model at the firm level give rise to effects that differ from those in a pure macro approach. It is harder to say with certainty whether the differences we observe are due to the differences in portfolio compositions of firms, or differences in the initial macroeconomic conditions.

\footnotetext{
${ }^{26}$ Note that we keep REMARK and TTLFS equal to their initial distributions $1991 Q 1$ and $1998 Q 1$ in the simulations because we have no model for the dynamics of these variables.
} 
Table 3: Absolute and relative default frequency distribution percentiles at different horizons $h$ into the future using the empirical model 1991Q1 and 1998Q1.

Absolute default frequency percentiles at horizon $h$ (quarters ahead) Time period $1991 Q 1$

Time period $1998 Q 1$

\begin{tabular}{ccccccccc} 
Percentile & $h=1$ & $h=4$ & $h=6$ & $h=8$ & $h=1$ & $h=4$ & $h=6$ & $h=8$ \\
\hline 95-percent & 2.02 & 2.73 & 2.97 & 2.78 & 0.99 & 0.99 & 0.99 & 1.01 \\
99-percent & 2.17 & 3.08 & 3.48 & 3.46 & 1.04 & 1.09 & 1.06 & 1.06
\end{tabular}

Relative default frequency percentiles at horizon $h$ (quarters ahead)

Time period 1991Q1 Time period 1998Q1

\begin{tabular}{lcccccccc} 
Percentile & $h=1$ & $h=4$ & $h=6$ & $h=8$ & $h=1$ & $h=4$ & $h=6$ & $h=8$ \\
\hline 95-percent & 0.30 & 0.67 & 0.85 & 0.82 & 0.13 & 0.18 & 0.19 & 0.20 \\
99-percent & 0.45 & 1.02 & 1.36 & 1.50 & 0.18 & 0.28 & 0.26 & 0.26
\end{tabular}

Notes: The absolute default frequency distribution percentiles have been determined from a distribution of 1,000 outcomes $h$ periods ahead by simulating the empirical model with shocks added to the domestic and foreign VAR-models, and to the VAR-model of the financial ratios. The relative default frequency percentiles have been determined from a distribution where a "trend-path" for the default frequency level (given by a simulation of the empirical model where no shocks are added to the economy using the same initial conditions) has been subtracted from the absolute default frequency level.

We learn two things from the results in Table 3. First, the empirical model correctly identifies that absolute default risks were substantially higher in 1991 than in 1998. The estimated percentiles cover the actual default frequencies during 1991-1992 and 1998-1999, even though the dummy variables REMARK and TTLFS are kept at their initial values throughout the simulations which tends to yield a downward/upward bias for the first/latter period. Second, and most importantly, we note that the relative default frequency distribution percentiles are at least two times larger for the 1991 portfolio of firms than for the 1998 portfolio of firms. This is a clear indication that the micro-data approach using the non-linear default-risk model differs substantially from a pure macro approach, because - as mentioned earlier - a pure macro approach implies that these numbers are the same.

This latter result is quite pronounced, although we have not taken into account in the estimated default-risk model that different industries might display different degrees of sensitivity to the macroeconomic stance. If this is the case, and if the composition of shares of firms in different industries has changed over time, then the results reported in Table 3 would be even more pronounced, and the evidence in favor of the micro-macro based approach even stronger. 


\subsection{Is there a trade-off between real and financial stability?}

In this subsection, we compute the impulse response functions to an identified monetary policy shock, and examine if there is a potential trade-off between stabilizing inflation and output and the default frequency. Following Lindé (2002), the monetary policy shock is identified using the so-called recursiveness assumption adopted by Christiano, Eichenbaum, and Evans (1999, 2005). The assumption being that goods market clear before and financial markets after the central bank sets the interest rate. In our empirical model, this implies that output and inflation do not react contemporaneously to a policy shock, whereas the real exchange rate and the default rate do react contemporaneously.

In Figure 8, we show the impulse response functions to a shock to monetary policy in the estimated VAR-model where the default rate is included as an endogenous variable. There are several features worth noting in this graph. According to the VAR, output and inflation fall after an increase in the interest rate, whereas the real exchange appreciates. ${ }^{27}$ As in many other studies (see e.g. Christiano, Eichenbaum and Evans, 2005), the maximum effects are quite delayed in time with peak effects after $1-2$ years. Simultaneously, there is a significant and persistent rise in the average default rate. Consequently, the results in Figure 8 suggest that there is a trade-off between stabilizing the inflation rate and the default rate for monetary policy. If the Riksbank at a given point in time would like to fight inflation more aggressively than prescribed by the rule normally followed, thereby injecting a positive policy shock (i.e., an unanticipated increase in the REPO rate), this would lead to increasing default frequencies according to the VAR.

However, if we do the same experiment in the empirical micro-macro model outlined in Section 4, the picture changes substantially. According to the micro-macro model, the potential trade-off between stabilizing the real economy (i.e., output and inflation) and financial stability (approximated by the default rate) is highly time-dependent. In Figures 9 and 10, we plot, for the portfolio of firms in $1991 Q 1$ and 1998Q1, the impulse response functions for an identical policy shock as in Figure 8 along with the impulse response functions in the estimated VARmodel where the default rate is endogenous. ${ }^{28}$ As can be seen from Figures 9 and 10, the point

\footnotetext{
${ }^{27}$ Note that the real exchange rate $q_{t}$ is defined as $s_{t}+p_{t}^{f}-p_{t}$, implying that a decrease in $q_{t}$ is an appreciation.

${ }_{28}$ The impulse response functions in the micro-macro model have been computed as follows. As initial conditions, we use how the portfolio look like in $1991 Q 4$ and $1998 Q 1$, along with the macroeconomic stance. We then compute a "trend path" by doing a dynamic simulation of the model when no shocks are hitting the economy, i.e. $u_{t}^{d}, u_{t}^{f}$ and $u_{i, t}^{y}$ are all zero and we use actual values on the macro variables $\{1990 Q 3,1990 Q 4\}$ and $\{1997 Q 3,1997 Q 4\}$ are used as starting values (two lags are used in the VARs). Let $X_{t+h}^{\text {trend }}$ denote the computed trend default rate at horizon $h=1,2, \ldots, 20$. Second, we make an additional simulation using exactly the same
} 
estimates for output, inflation and the default rate are quite different in the micro-macro model compared with the aggregate VAR-approach. For 1991Q1, the impulse response functions are roughly the same as in the aggregate VAR-model, although the persistence in the default rate is somewhat lower due to the fact that there is a substantial amount of intrinsic persistence for that variable in the VAR, but none in the default-risk model. Turning to 1998Q1, however, we see that the point estimates of the same sized policy shock are rather different in the micromacro model compared with the aggregate VAR-model. The effects on the aggregate default frequency are considerably less pronounced according to the micro-macro model than in the aggregate VAR. Moreover, the different response of the default rate implies that the impulse response functions for output and inflation are very different. In the 1998Q1-period, effects on inflation are less than half compared with those in the estimated VAR.

Given that the uncertainty about the parameters in the VAR-model (1) is rather high, we cannot claim that the point estimates for the micro-macro model reported in Figures 9 and 10 are significantly different from the ones in the aggregate VAR in a statistical sense. But if the micro-macro model is a more realistic model than the aggregate VAR-model (we will discuss this issue in greater detail the next subsection), then the effects of monetary policy on the economy are state-dependent. This possibility has interesting implications for policy from an economic point of view. In this case, monetary policy is a potent tool for stabilizing the economy in recessions in the sense that small unexpected movements in the interest rate have relatively large effects on the economy. But in booms, when macroeconomic conditions are favorable and firms' balance sheets strong, monetary policy is a less potent tool for stabilizing the economy, i.e., the central bank must inject much larger policy shocks in order to fight inflation (at the cost of driving up the default frequency). An interesting question, of course, is whether most of these effects come from differences in macroeconomic stance rather than changes in the balance-sheet variables of the firms in the portfolio. Unfortunately, we cannot provide a clear-cut answer to this question. The reason being that the formation of the population of existing firms in a given period is most likely dependent on the stance of the macroeconomy. Nevertheless, the estimation results for the default-risk models I and III suggest that the macroeconomic stance might play a larger role than firms' balance sheets.

initial conditions but this time we allow for the policy shock hitting the economy (i.e. $u_{t}^{d}$ is non-zero). Let $X_{t+h}^{\text {shock }}$ denote the computed default rate at horizon $h=1,2, \ldots, 20$ in this case. The impulse responses are then computed as $X_{t+h}^{\text {shock }}-X_{t+h}^{t r e n d}$ for each variable in $X$. 


\subsection{Joint forecasts of default-frequency and inflation}

In this last subsection, we use the micro-macro model to produce joint forecasts of the defaultfrequency and inflation rate. We use the same initial conditions as in the previous sections and for the same two quarters, 1991Q1 and 1998Q1, i.e., the beginning of a recession and the beginning of a boom in the economy. To produce these forecasts and associated uncertainty bands, we perform 1,000 dynamic simulations with the estimated model 8 quarters into the future. This produces 1,000 projections in periods $t+1, \ldots, t+8$ for the aggregated default frequency and inflation rate. The resulting forecasts and uncertainty bands are shown in the left-hand panels of Figures 11 and 12. The right-hand panels display corresponding results for the VAR-model (1). The dashed lines are the median forecasts and the dotted lines represent the 2.5 and 97.5 percentiles in the simulated distributions. The solid lines show the actual outcomes for $1991 Q 2-1993 Q 1$ and for $1998 Q 2-2000 Q 1$. There are a couple of interesting features worth noting. First, the micro-macro model appears to forecast actual inflation and default frequency quite well, although for the forecasts starting in 1998Q1, actual default frequency is outside the 95 percent confidence interval in one quarter. It should be noted that since the default risk model is only estimated on data up to 1999 Q2, this forecast is to some extent out-of-sample. Second, confirming the results reported in Table 3, we see that the uncertainty is much lower in the $1998 Q 1$ forecast. The 95 percent confidence interval for the predicted default frequency in $1993 Q 1$ is between 1.3 and 3.2 percent, whereas the interval for $2000 Q 1$ is roughly between 0.6 and 1.0 percent. The confidence intervals for VAR-model forecasts are of equal width in both period, suggesting an under-estimation of uncertainty in the first period and an over-estimation in the latter period. In comparison with the aggregate VAR-model, the micro-macro model produce a much more plausible picture in that default risk is more severe in the beginning of the 1990s, whereas the band width is very tight in the late 1990s, suggesting a very low risk of financial distress. As noted by Christoffersen (1998), this is a desirable property of a forecasting model. A similar, but less pronounced, interpretation can be done for the inflation rate forecasts. Given an extended data set it would, of course, be very interesting to compare the genuine outof-sample forecasts properties of the micro-macro model and the VAR-model (comparing RMSE and forecasting distributions, see Christoffersen, 1998). 


\section{Conclusions}

In this paper, we have studied the interaction between real economic activity and the financial stance of the economy using reduced form methods. To this end we have acquired a large panel data set for the Swedish economy during 1990 - 1999. A period covering a banking crises episode and associated deep recession in the early 1990s, as well as a boom in the latter part of the 1990s.

Our empirical results provide support for the idea that the financial stance of the economy matters for real economic activity. We argue on empirical grounds that the aggregate default frequency is a good proxy for measuring the financial stance, at least this seems to be case for Sweden. Other financial indicator variables such as stock prices, term structure or the supply loans do not carry information for aggregate quantities and prices, whereas on the other hand housing prices do. We leave for future research to examine the role of housing prices. Moreover, we find that a simple logit model for default at the firm level using both firm-specific and macroeconomic variables as explanatory variables can explain the extremely high default frequencies during the banking crisis in the beginning of the 1990s, and also the considerably lower default frequencies in the late 1990s. Furthermore, we find strong evidence that most of the variation in balance-sheet variables are due to idiosyncratic shocks. Finally, we show that augmenting a standard macroeconomic model with predicted aggregated default-frequencies from the logit model and a simple dynamic panel for the balance-sheet variables will produce state-dependent effects of monetary policy that are quantitatively important. According to our model, monetary policy is a more potent tool for stabilizing the economy during recessions than in booms, when the effects of monetary policy are rather limited. These latter results provide some implicit empirical support for the existence of a so-called credit channel of monetary policy.

In our view, the results in the paper suggest that central banks should consider integration of the analyses of financial stability and economic activity. The empirical micro-macro model developed in the paper is an example of a simple empirical model which can be used for such a purpose.

The analysis conducted in the paper should be improved and expanded in a variety of ways. First, it would be of interest to examine the out-of-sample forecasting performance of the estimated logit model, i.e., whether the estimated model can accurately predict the default frequency rates for the year 2000 and onwards. Another promising research direction is to condition on firms' industry-classification, both in the default-risk model and in the dynamic panel VAR for the balance-sheet variables. Presumably, one reason why the macroeconomic 
variables come out as very important in the estimated logit-model is that they capture systematic industry differences in firm-specific variables. Estimating the logit model on industry data would be a stronger test of whether the empirically important role for the macroeconomic variables is spurious or not. Conditioning on industry would also be a natural way to examine the robustness of the results pertaining to the role of aggregate vs. idiosyncratic shocks for the balance-sheet variables. Third, we need to think about the theoretical arguments for macroeconomic factors to enter as separate regressors in the default-risk model. 


\section{References}

Altman, Edward I., (1968), Financial ratios, discriminant analysis and the prediction of corporate bankruptcy, Journal of Finance, Vol. XXIII No. 4, pp. 589-611.

Altman, Edward I., (1971), Railroad bankruptcy propensity, Journal of Finance, Vol. XXVI No. 2, pp. 333-345.

Altman, Edward I., (1973), Predicting Railroad bankruptcies in America, Bell Journal of Economics, No. 4 (1), pp. 184-211.

Altman, Edward I., (1984), The success of business failure prediction models, Journal of Banking and Finance, No. 4, pp. 171-198.

Altman, Edward I., and Anthony Saunders, (1997), Credit risk measurement: developments over the last twenty years, Journal of Banking and Finance, No. 21 (11-12), pp. 1721-42.

Altman, Edward I., and Anthony Saunders, (2001), An analysis and critique of the BIS proposal on capital adequacy and ratings, Journal of Banking and Finance, No. 25 (1), pp. 25-46.

Arellano, Manuell, and Stephen Bond, (1991), "Some Tests of Specification for Panel Data: Monte Carlo Evidence and an Application to Employment Equations", Review of Economic Studies, Vol. 58, No. 2, pp. 277-297.

Bernanke, Ben, (1983), Nonmonetary effects of the financial crisis in the propagation mechanism of the Great Depression, American Economic Review Vol. 73 No.3, pp. 257-276.

Bernanke, Ben, (1993), Nonmonetary effects of the financial crisis in the propagation mechanism of the Great Depression, Federal Reserve Bank of New York Quarterly Review 18(1), pp. $50-70$.

Bernanke, Ben, and Mark Gertler, (1989), Agency costs, net worth and business fluctuations, American Economic Review Vol. 79 No.1, pp. 14-31.

Bernanke, Ben, and Mark Gertler, (1990), Financial fragility and economic performance, Quarterly Journal of Economics 105(1), pp. 87-114.

Bernanke, Ben, and Mark Gertler, (1995), Inside the black box: the credit channel of monetary policy transmission, Journal of Economic Perspectives 9(4), pp. 27-48.

Bernanke, Ben, Mark Gertler and Simon Gilchrist, (1996), The financial accelarator and the flight to quality, Review of Economics and Statistics Vol. LXXVIII No.1, pp. 1-15.

Calomiris, Charles, and R. Glenn Hubbard, (1989), Price flexibility, credit availability and economic fluctuations: evidence from the U.S., 1894-1909, Quarterly Journal of Economics $104(3)$, pp. 429-452.

Carey, Mark and Mark Hrycay, (2001), Parameterizing credit risk models with rating data, Journal of Banking and Finance, 25, pp. 197-270.

Carling, Kenneth, Tor Jacobson, Jesper Lindé, and Kasper Roszbach, (2004), "Corporate Credit Risk

Modelling and the Macroeconomy", manuscript, Sveriges Riksbank.

Christiano, Lawrence J., Eichenbaum, Martin and Charles L. Evans, (1999), "Monetary Policy Shocks: What have We Learned and to What End", Chapter 2 in John B. Taylor and Michael Woodford (Eds.), Handbook of Macroeconomics, Vol. 1A, Elsevier Science, Amsterdam.

Christoffersen, Peter F., (1998), "Evalutating Interval Forecasts", International Economic Review, Vol. 39, No. 4, pp. 841-862. 
Christiano, Lawrence J., Eichenbaum, Martin and Charles L. Evans, (2005), "Nominal Rigidities and the Dynamic Effects of a Shock to Monetary Policy", Journal of Political Economy, forthcoming.

Coe, Patrick, (2002), Financial crisis and the Great Depression: a regime switching approach, Journal of Money, Credit and Banking 34(1), pp. 76-93.

Englund, Peter, (1999), The Swedish banking crisis: roots and consequences, Oxford Review of Economic Policy, 15 (3) Autumn, pp. 80-97.

Frydman, Halina, Edward I. Altman, and Duen-Li Kao, (1985), Introducing recursive partitioning for financial classification: the case of financial distress, Journal of Finance, Vol. XL, No. 1, pp. 269-291.

Gertler, Mark, and Simon Gilchrist, (1993), The role of credit market imperfections in the transmission of monetary policy: arguments and evidence, Scandinavian Journal of Economics 95(1), pp. 43-64.

Gertler, Mark, and Simon Gilchrist, (1994), Monetary policy, business cycles and the behavior of small manufacturing firms, Quarterly Journal of Economics 109, pp. 309-340.

Gordy Michael B., (2000a), A comparative anatomy of credit risk models, Journal of Banking and Finance, 24, No 1-2, pp. 119-149.

Jacobson, Tor and Jesper Lindé, (2000), Credit rating and the business cycle: can bankruptcies be forecast?, Sveriges Riksbank Economic Review, 2000, No 4, pp. 11-33.

Laitila, Thomas, (1993), "A Pseudo- $R^{2}$ Measure for Limited and Qualitative Dependent Variable Models", Journal of Econometrics, No. 56, pp. 341-356.

Lindé, Jesper, (2002), "Monetary Policy Shocks and Business Cycle Fluctuations in a Small Open Economy: Sweden 1986-2002", manuscript, Sveriges Riksbank.

Lowe, Philip, (2001), Maintaining financial stability: possible policy options, Sveriges Riksbank Economic Review 2001(2), pp. 25-33.

Ludvigson, Sidney, (1998), The channel of monetary transmission to demand: evidence from the market for automobile credit, Journal of Money, Credit and Banking, Vol. 30 No. 3, pp. 365-383.

Peek, Joe, and Eric Rosengren, (2000), Collateral damage: effects of the Japanese bank crisis on real activity in the United States, American Economic Review 90(1), pp. 30-45.

Platt, Harlan D., and Marjorie B. Platt, (1991), A note on the use of industry-relative ratios in bankruptcy prediction, Journal of Banking and Finance, Vol 15, pp. 1183-1194.

Poole. William, (1993), Credit Veils and credit realities, Federal Reserve Bank of New York Quarterly Review 18(1), pp. 83-85.

Repullo, Rafael, and Javier Suarez, (2000), Entrepreneurial moral hazard and bank monitoring: a model of the credit channel, European Economic Review 44, pp. 1931-1950.

Samolyk, Katherine, (1994), Banking conditions and regional economic performance: evidence of a regional credit channel, Journal of Monetary Economics 34(2), pp. 259-278.

Shumway, Tyler, (2001), Forecasting bankruptcy more accurately: a simple hazard model, Journal of Business, Vol 74, No 1, pp. 101-124.

Wilson, Thomas, (1997), Portfolio credit risk (I), Risk,Vol. 10, No. 9, pp. Xx-xx+5. 

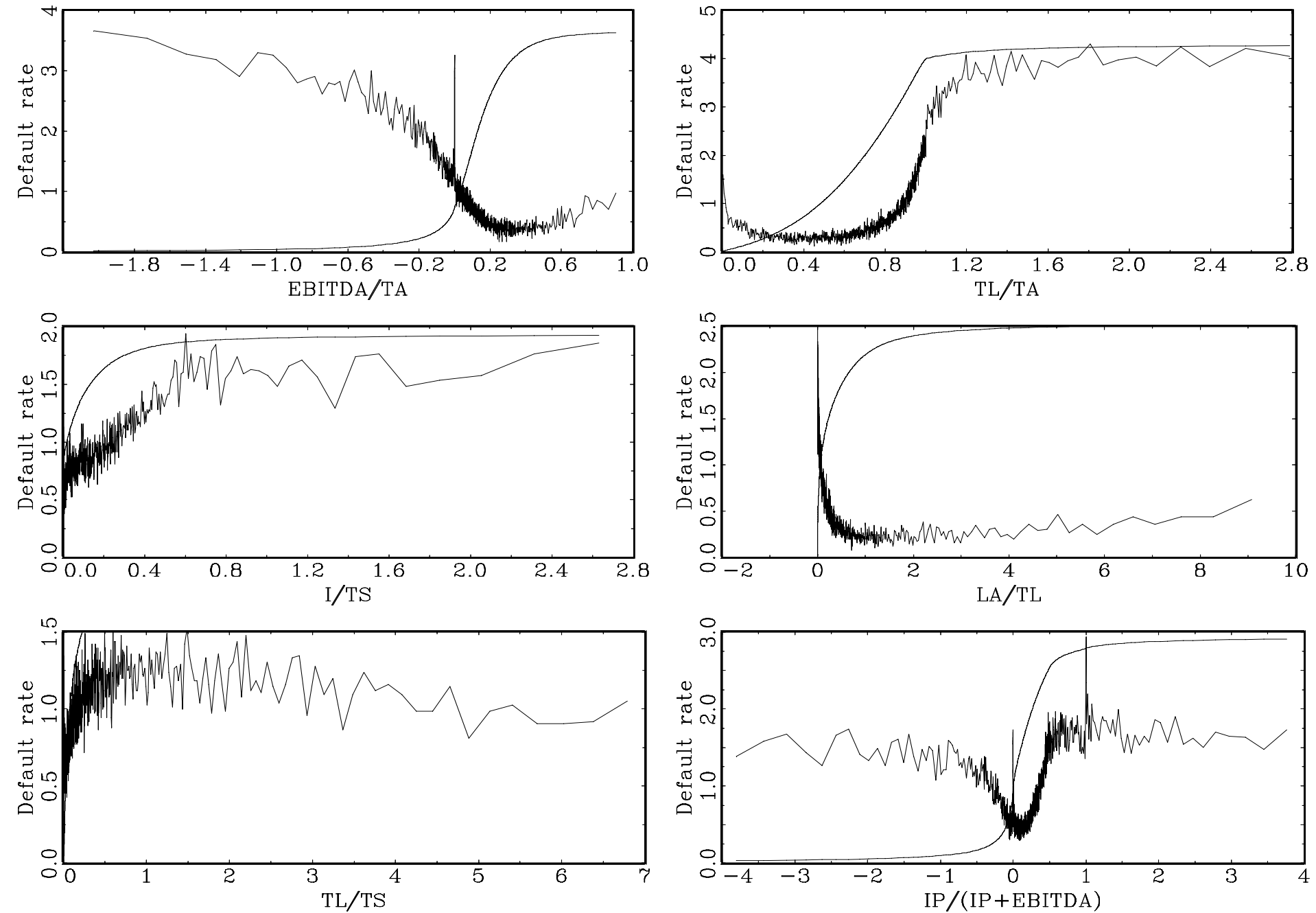

Figure 1: Default rates and the cumulative distribution functions for the accounting data. 

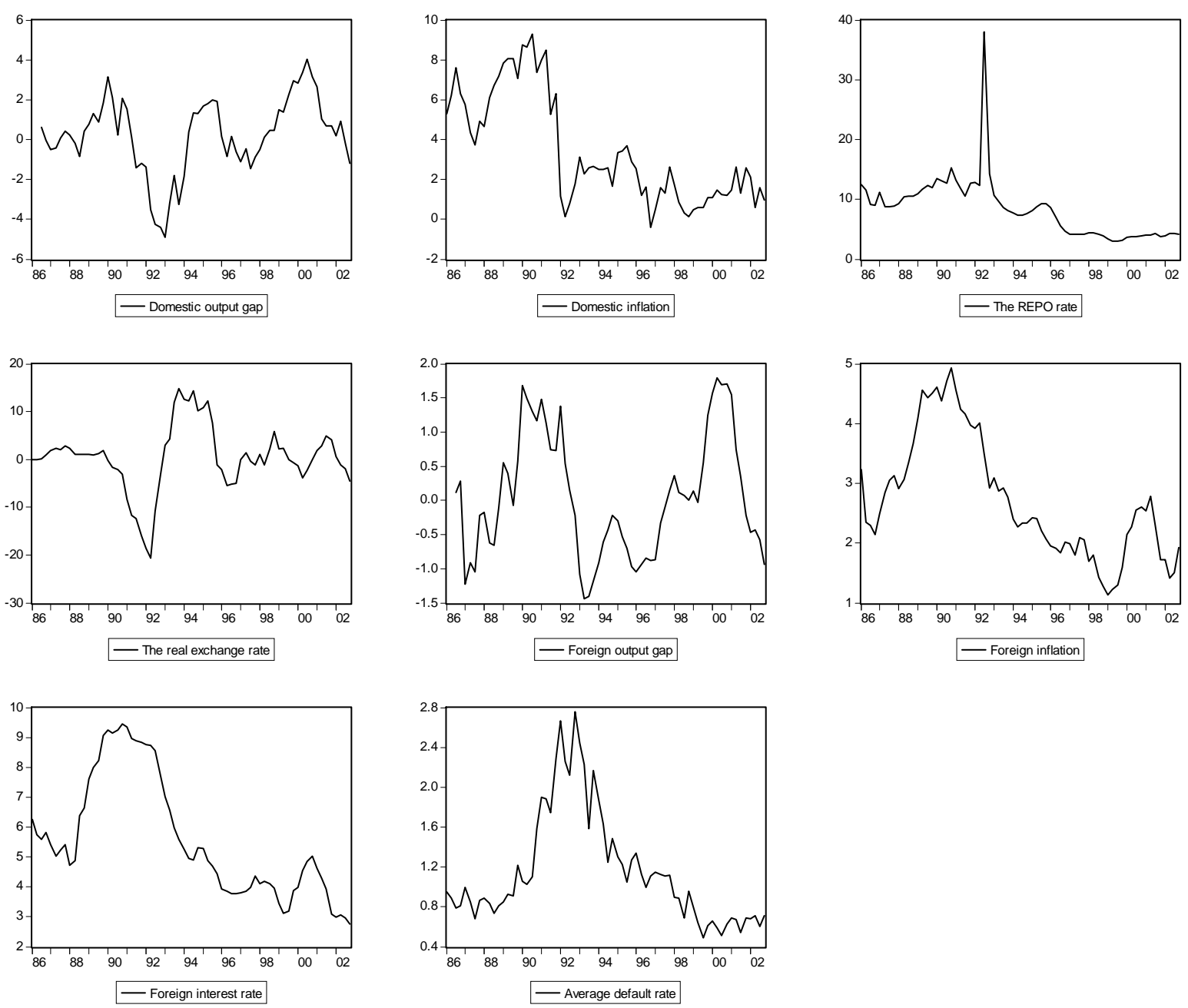

Figure 2: Macro data used in the estimated VAR models. 

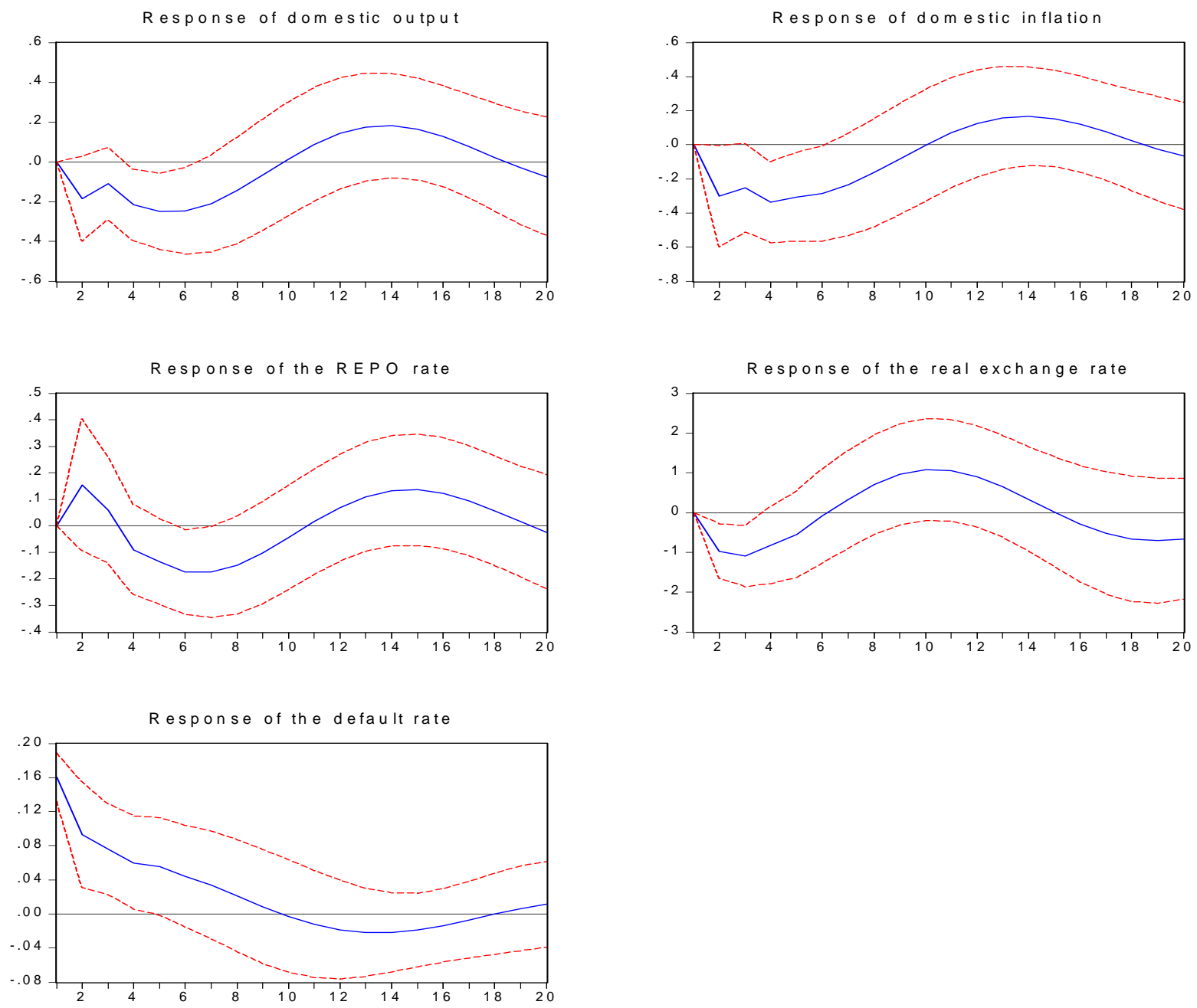

Figure 3: Impulse response functions to a aggregate default frequency shock in the estimated VAR where default frequency is included in $X_{t}$. 


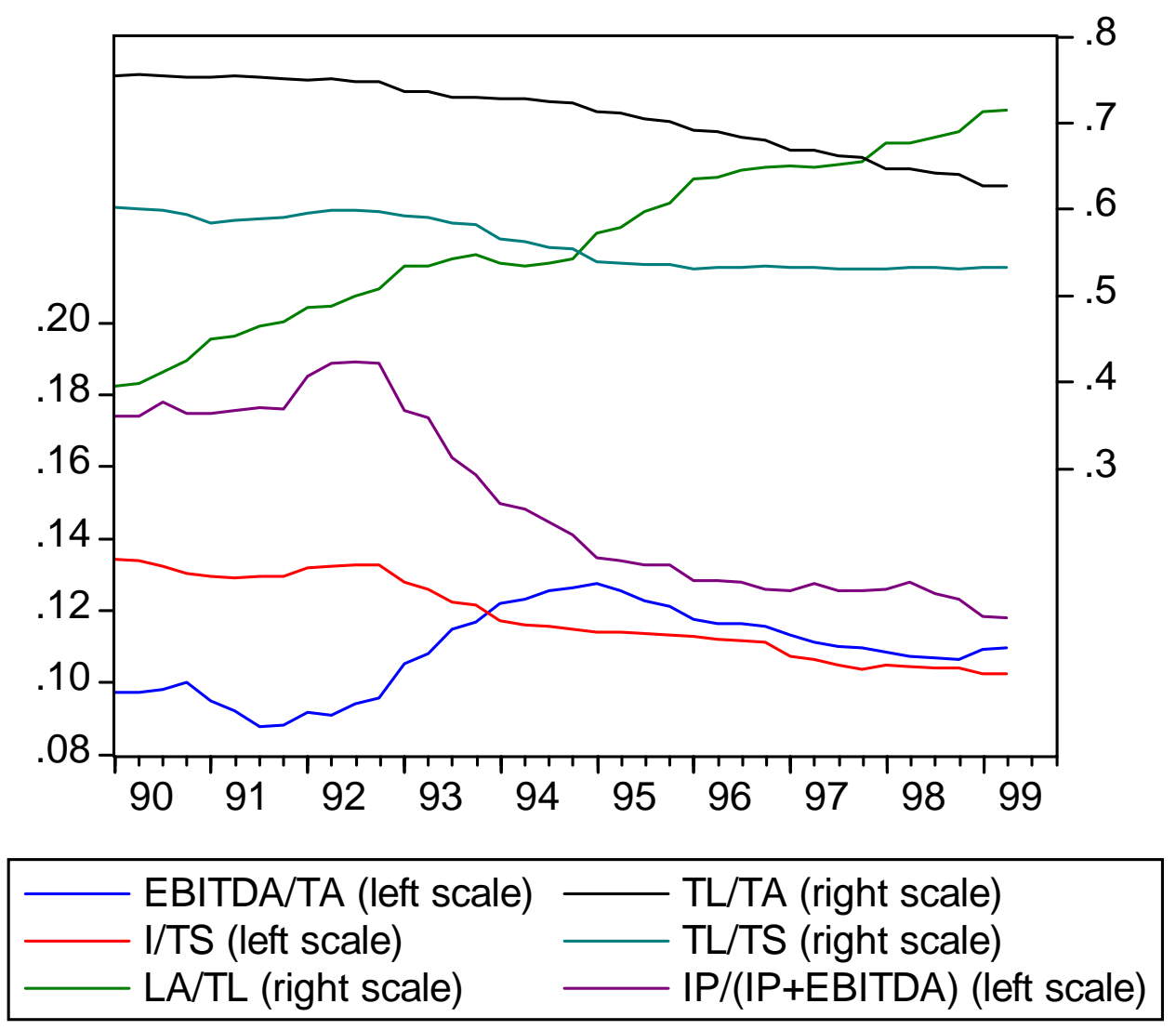

Figure 4: Averaging accounting data over time 1990Q1 - 1999 Q2 in the panel. 


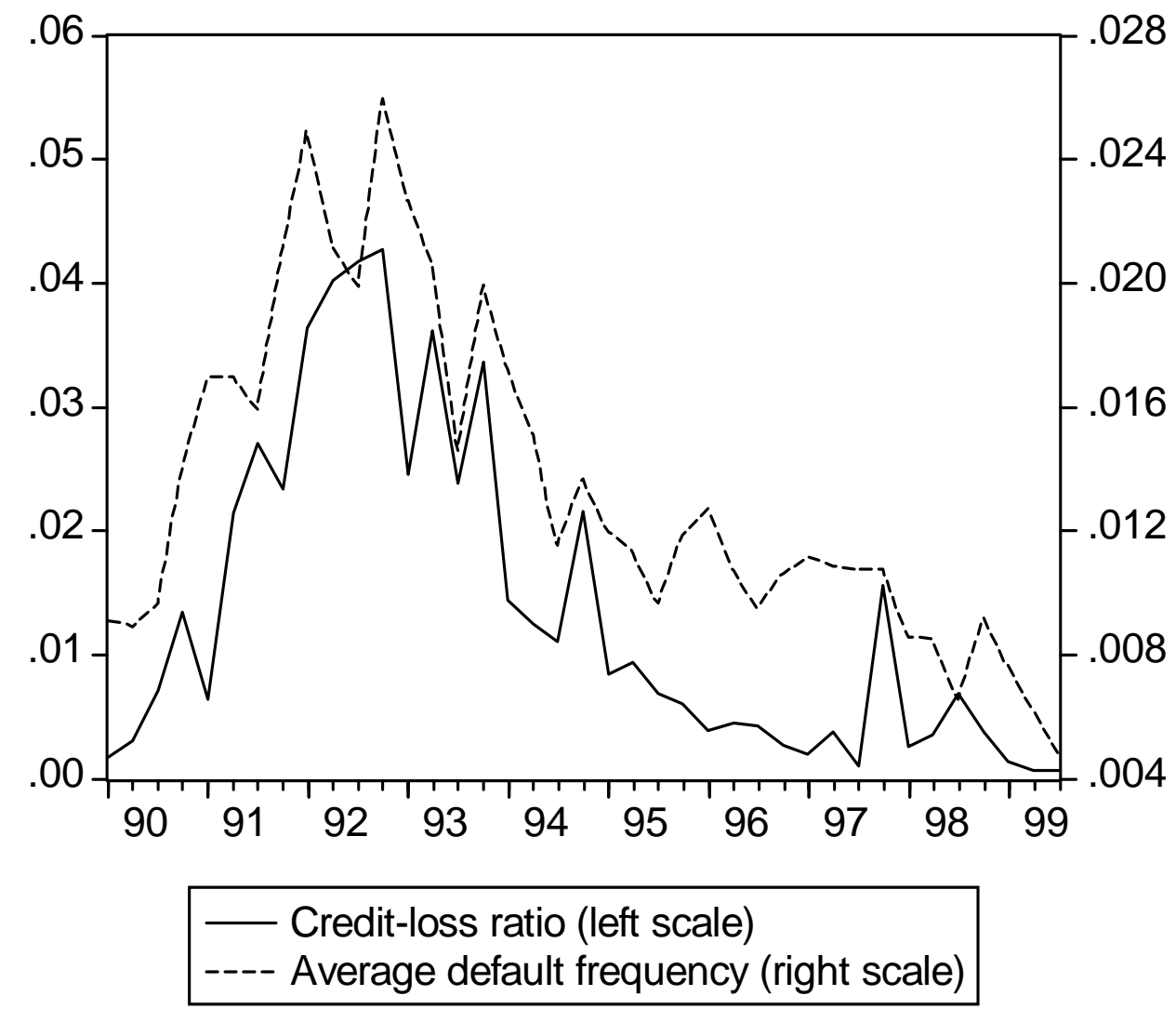

Figure 5: Average default frequency over time in the panel and credit losses by non-financial firms relative to loan stock. 


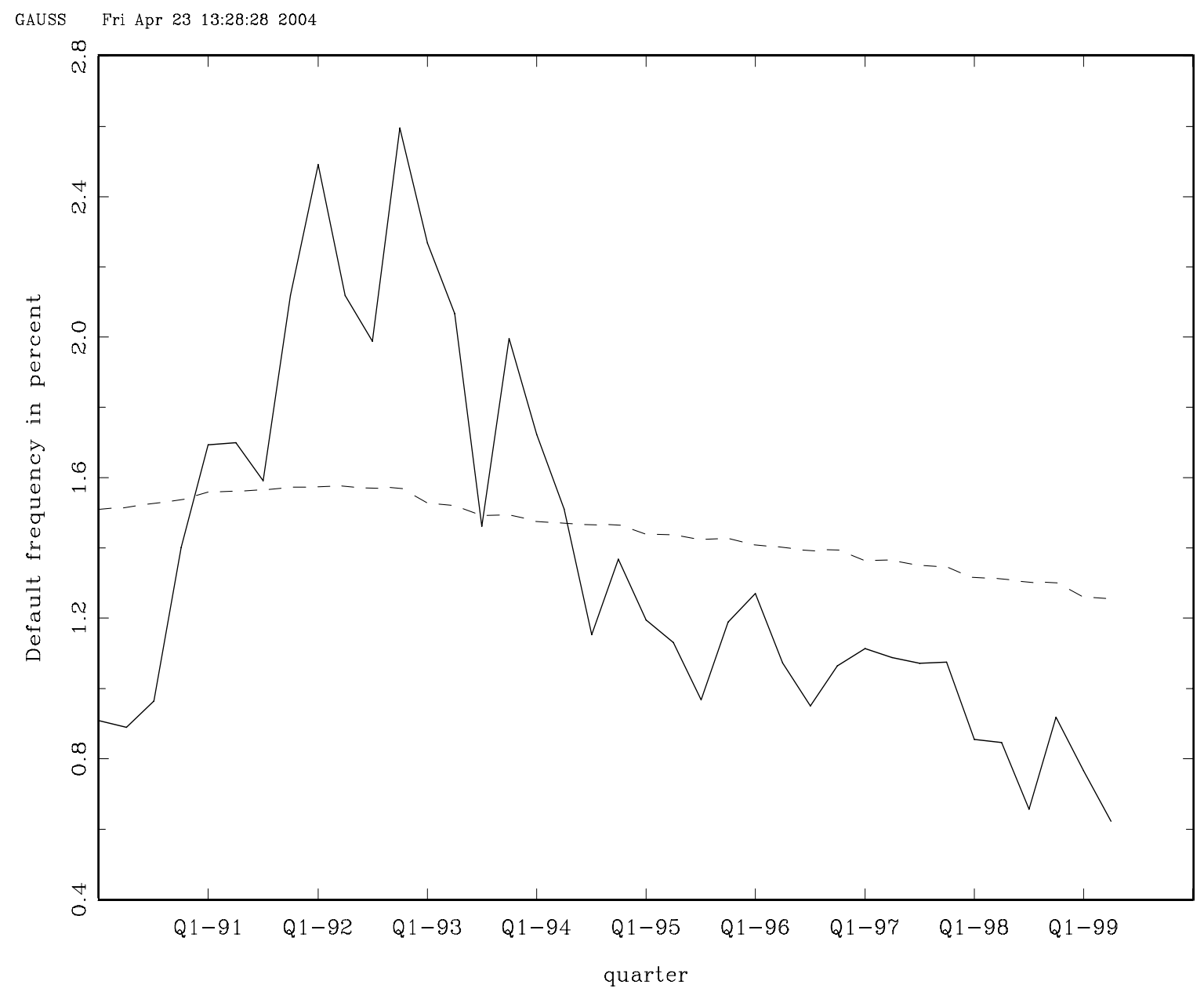

Figure 6: Actual and projected default rates at the aggregate level in the estimated default-risk model with only balance sheet variables included (Model I). 


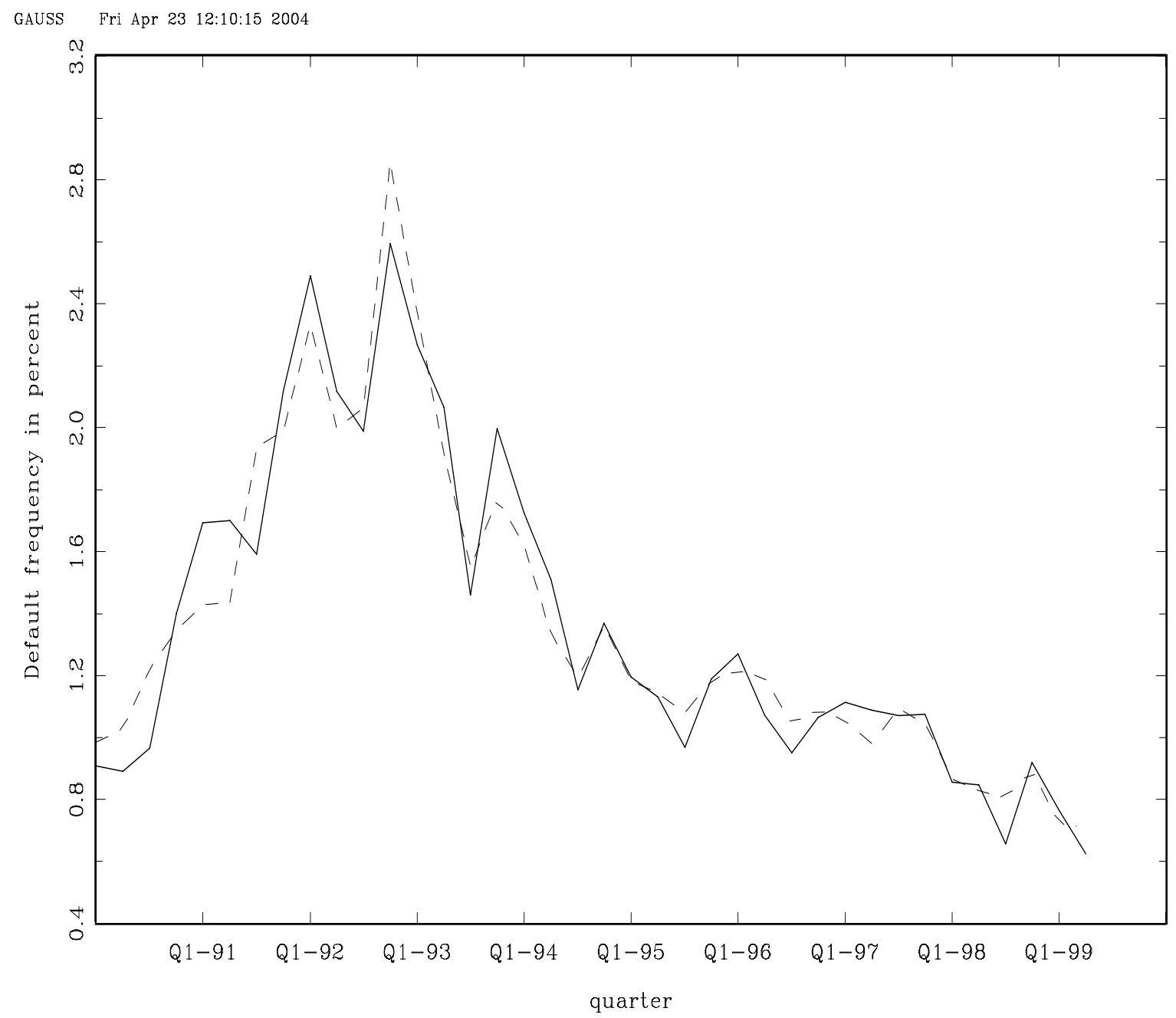

Figure 7: Actual and projected default rates at the aggregate level in the estimated default-risk model with macro variables (Model III). 

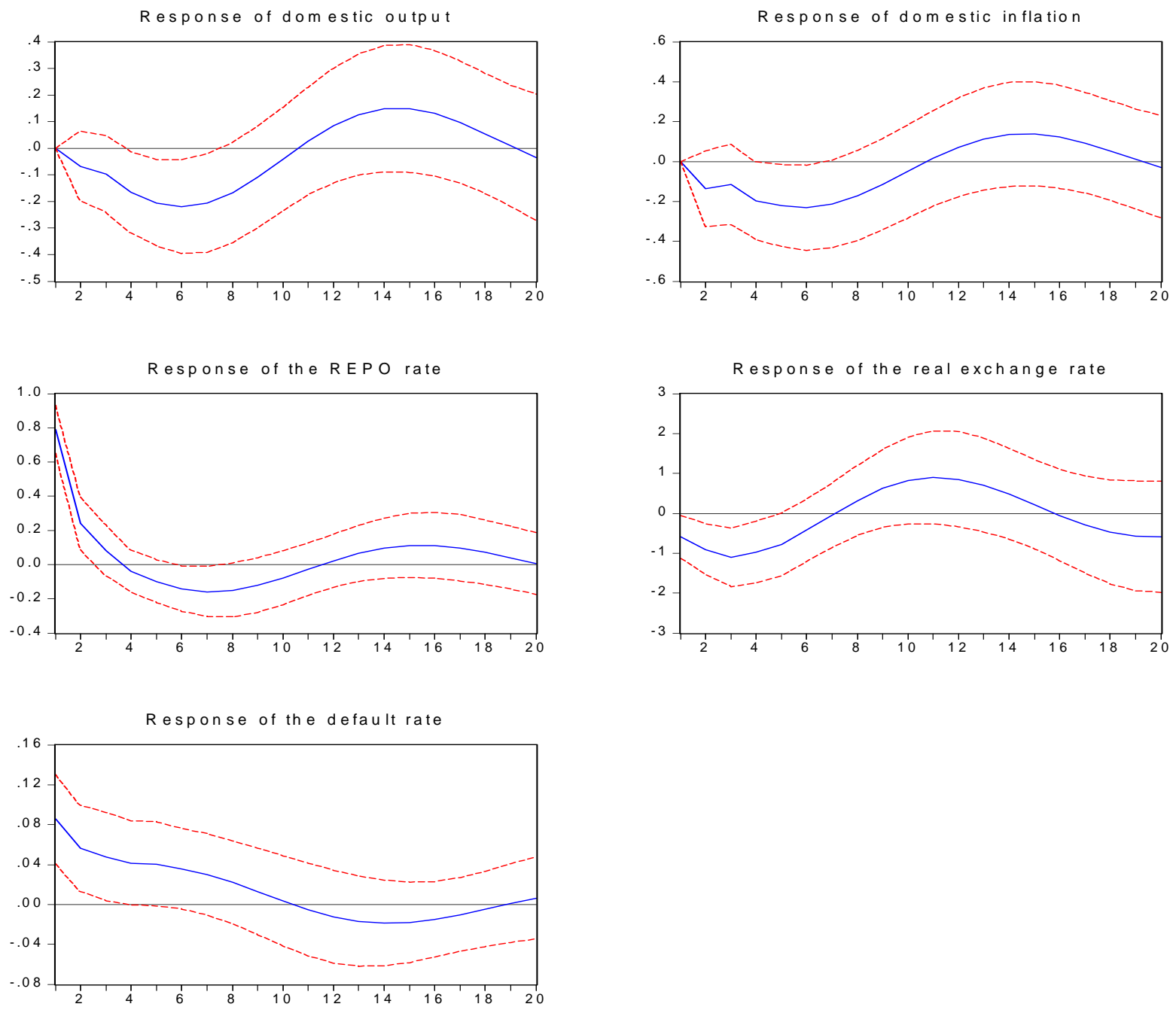

Figure 8: Impulse response functions to an identified shock to monetary policy in the VAR model where the default rate is endogenous. Solid line shows point estimates and dashed lines 95 percent confidence interval. 
Output

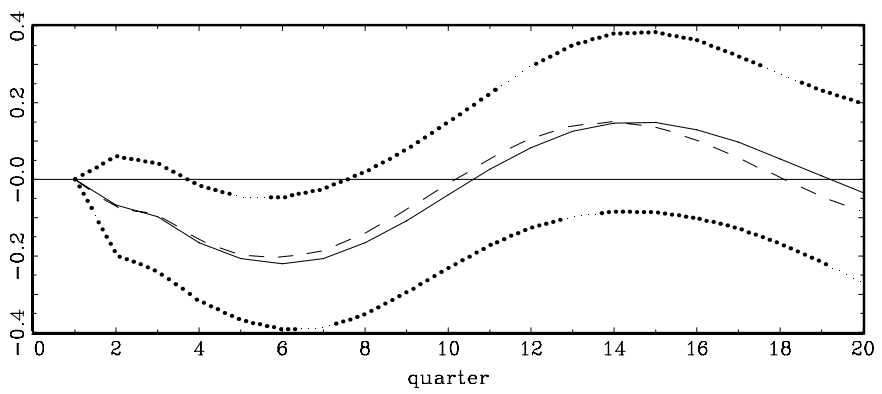

REPO rate (APR)

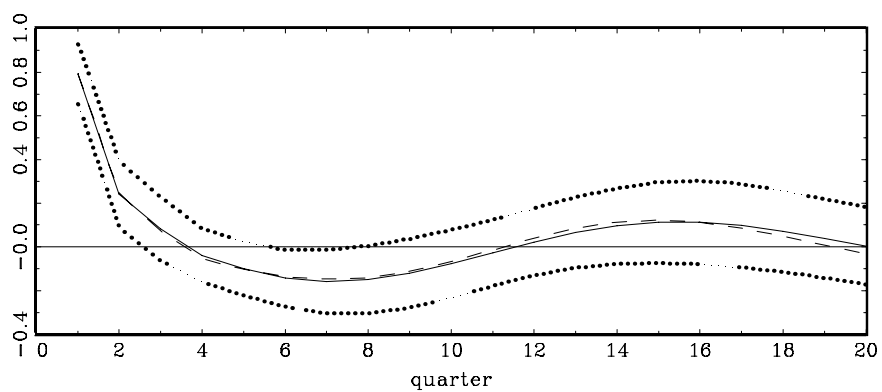

Default rate

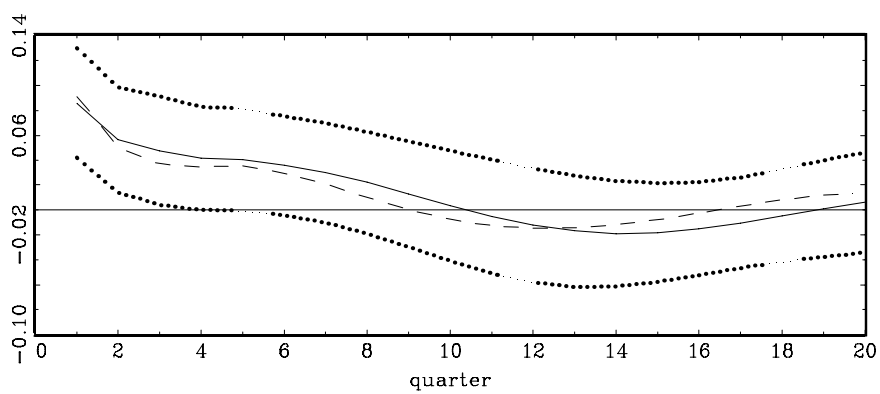

Inflation (APR)

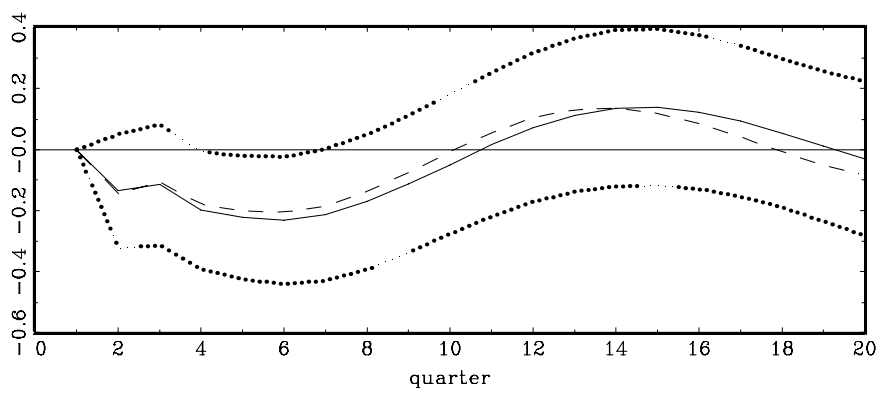

Real exchange rate

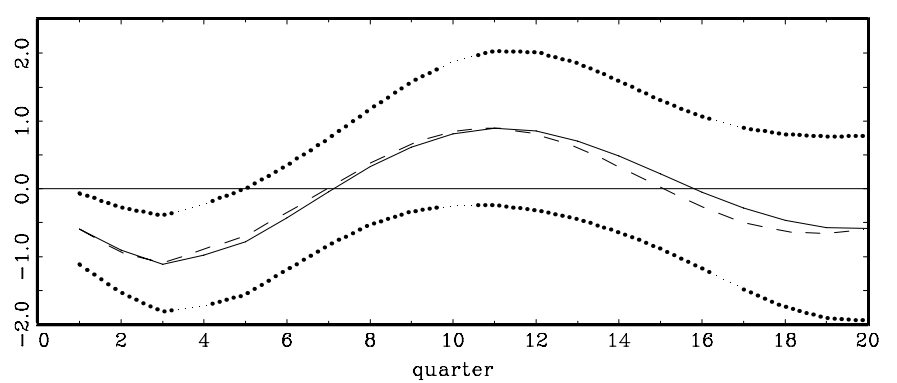

Figure 9: Impulse response functions in the estimated VAR model with the default rate endogenous (point estimates - solid line, dotted lines shows 95 percent confidence interval) and in the empirical micro-macro model (dashed line) for 1991Q1. 
Output

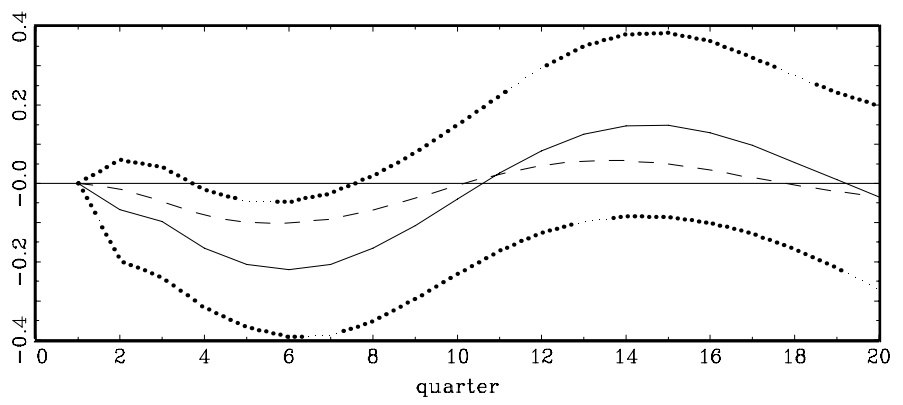

REPO rate (APR)

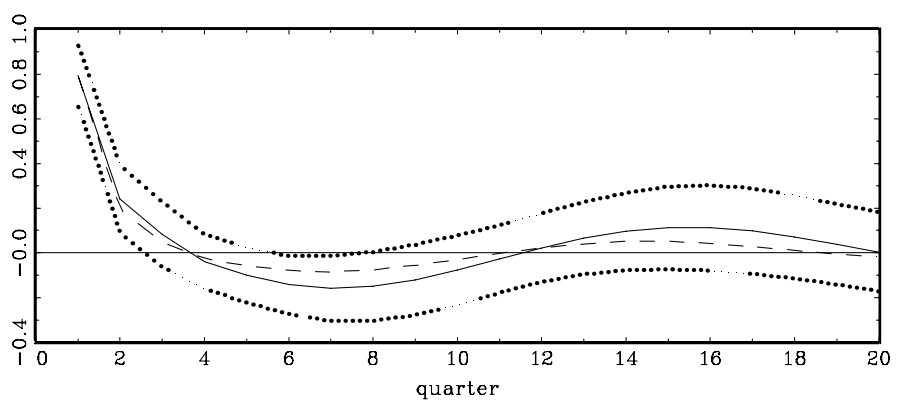

Default rate

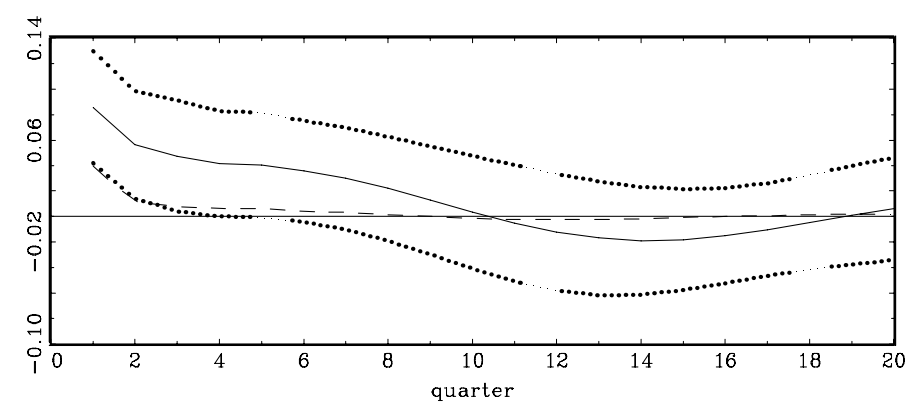

Inflation (APR)

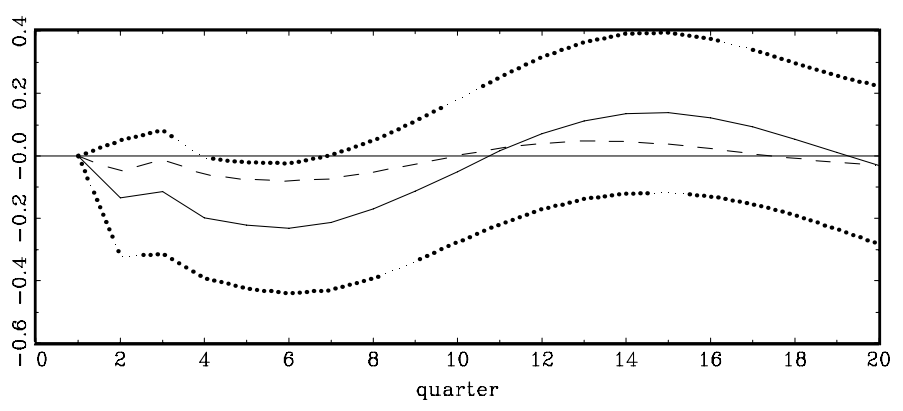

Real exchange rate

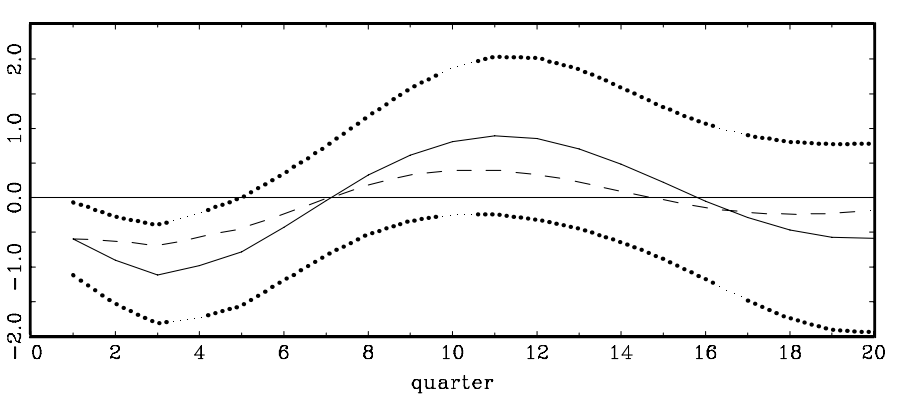

Figure 10: Impulse response functions in the estimated VAR model with the default rate endogenous (point estimates - solid line, dotted lines shows 95 percent confidence interval) and in the empirical micro-macro model (dashed line) for 1998Q1. 

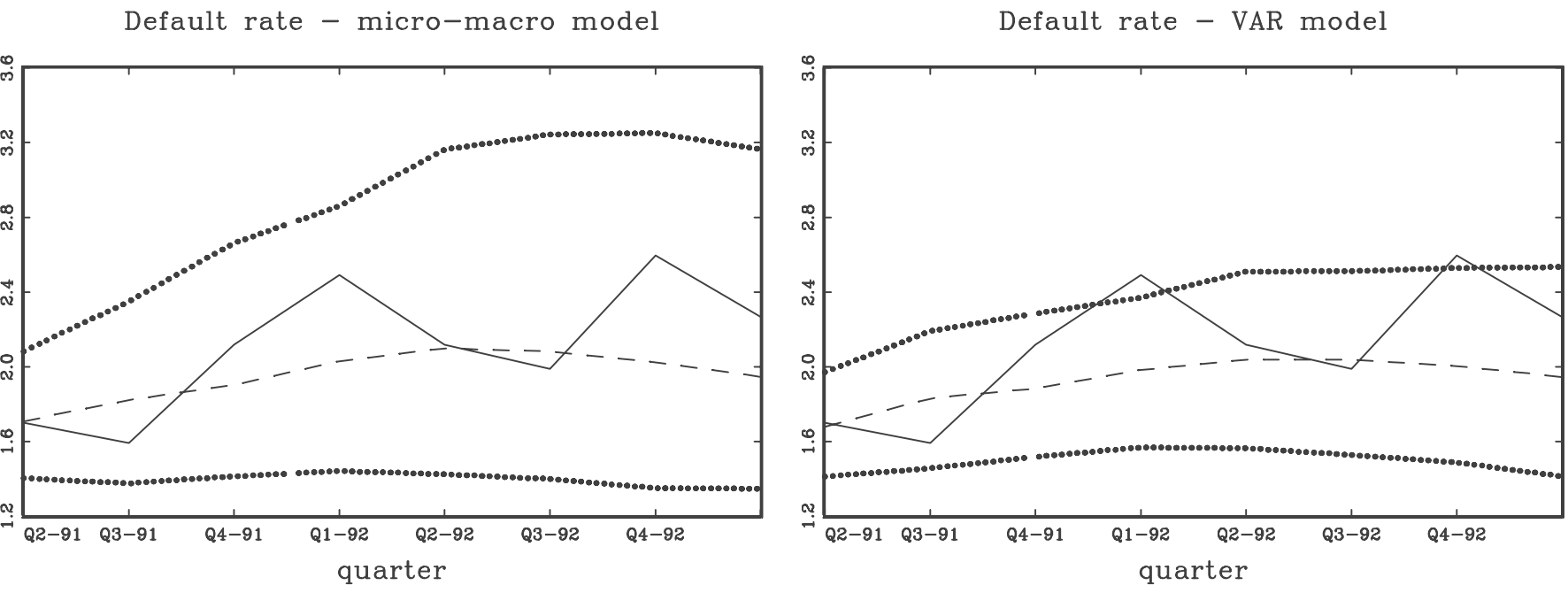

Inflation rate - micro-macro model

Inflation rate - VAR model
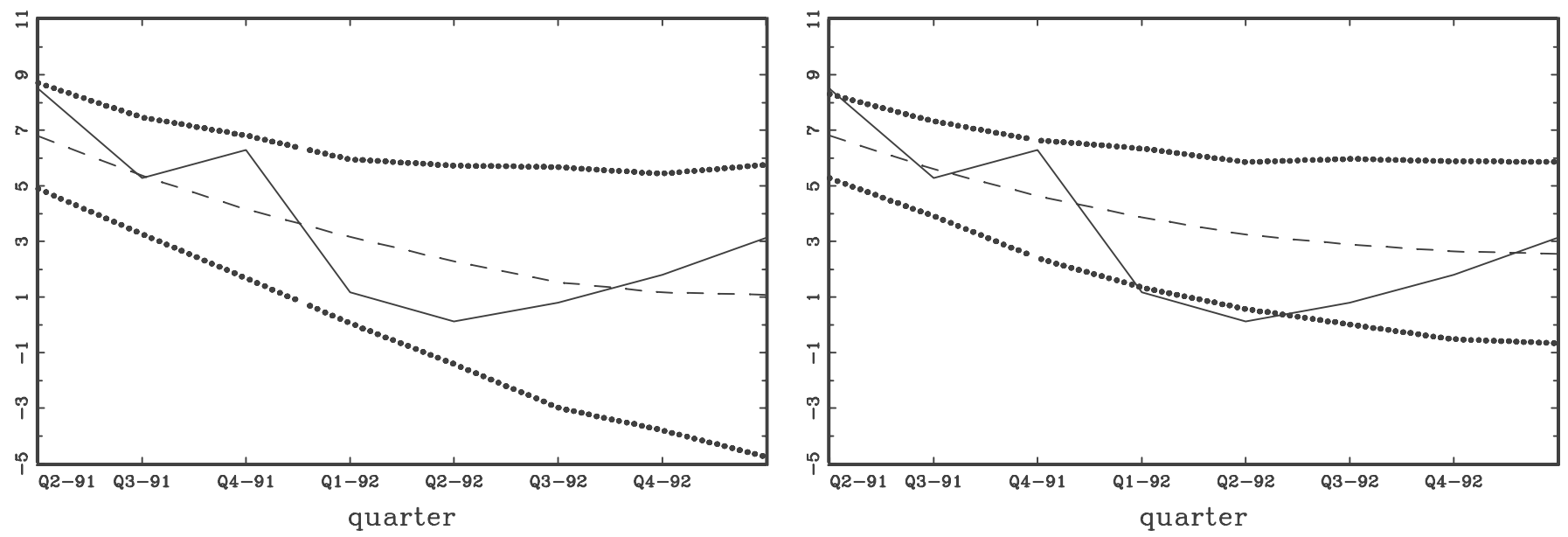

Figure 11: Joint dynamic forecasts of the default frequency and inflation 8 quarters ahead starting 1991Q1. The left panel shows the results for the micro-macro model, and the right panel the results for the VAR model where the aggregate default rate is included as an endogenous variable. The dashed line is the median forecast, and the dotted lines indicate the 95 percent confidence interval. The solid line shows the actual outcome. 
Default rate - micro-macro model

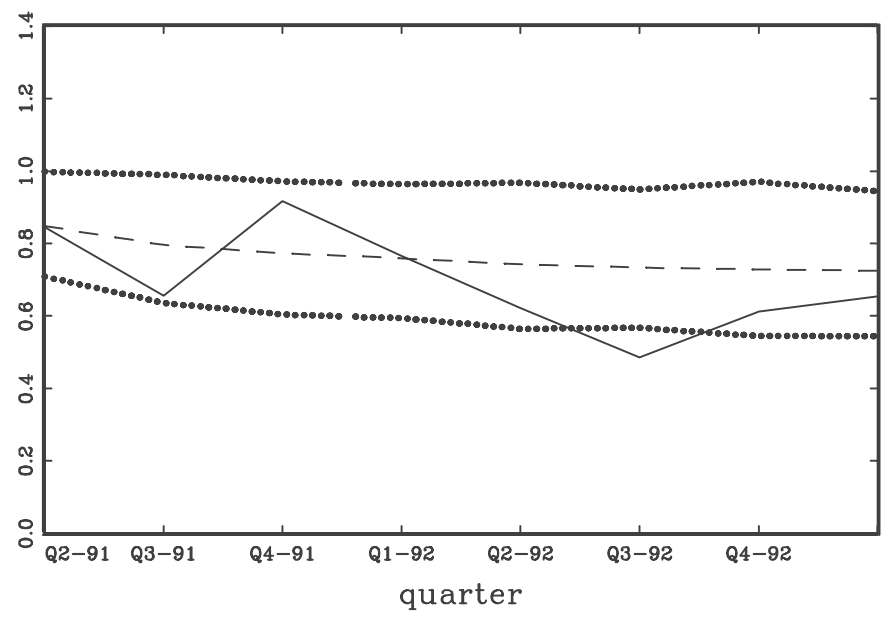

Inflation rate - micro-macro model

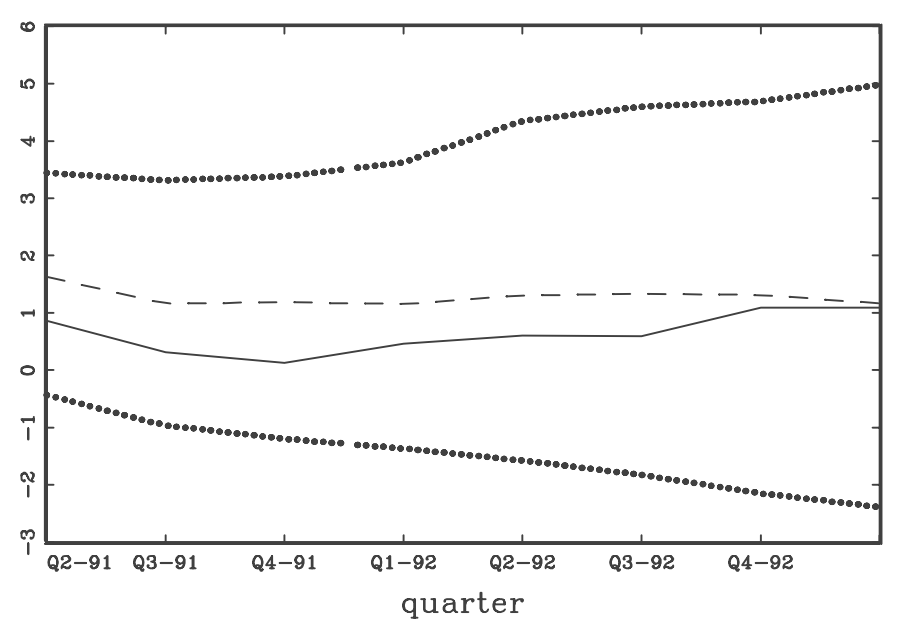

Default rate - VAR model

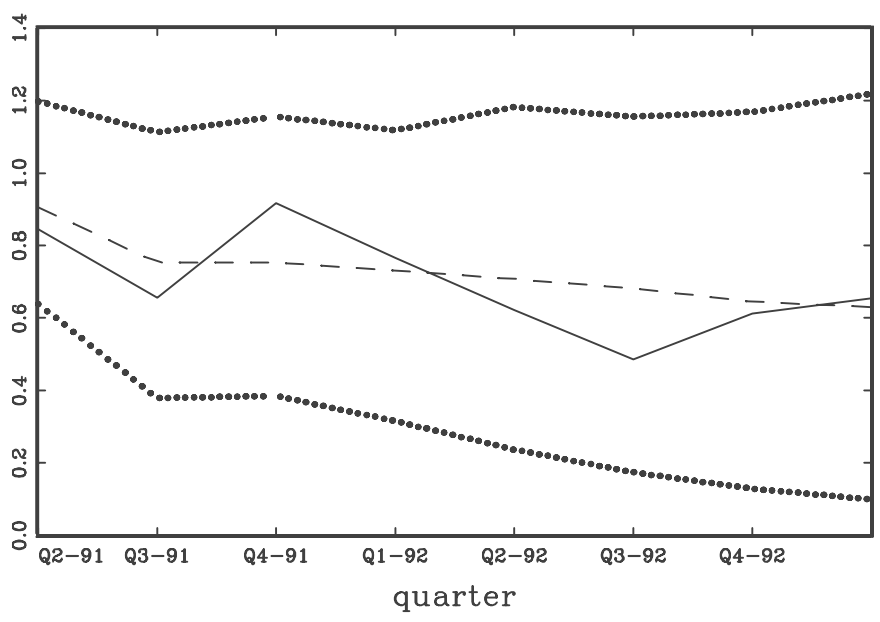

Inflation rate - VAR model

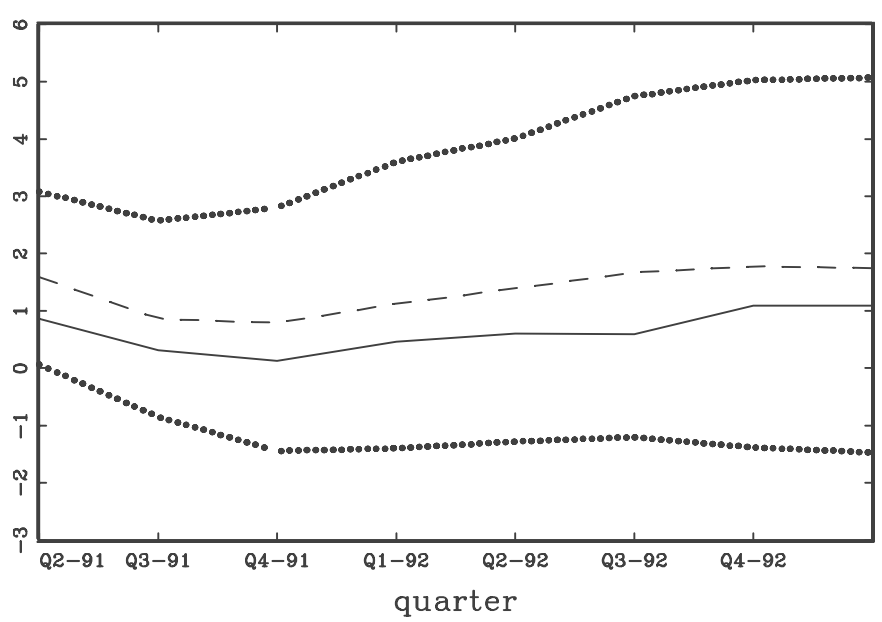

Figure 12: Joint dynamic forecasts of the default frequency and inflation 8 quarters ahead starting 1998Q1. The left panel shows the results for the micro-macro model, and the right panel the results for the VAR model where the aggregate default rate is included as an endogenous variable. The dashed line is the median forecast, and the dotted lines indicate the 95 percent confidence interval. The solid line shows the actual outcome. 


\section{Earlier Working Papers:}

For a complete list of Working Papers published by Sveriges Riksbank, see www.riksbank.se

An Alternative Explanation of the Price Puzzle by Paolo Giordani

Interoperability and Network Externalities in Electronic Payments by Gabriela Guibourg................ 2001:126

Monetary Policy with Incomplete Exchange Rate Pass-Through by Malin Adolfson ..... 2001:127

Micro Foundations of Macroeconomic Price Adjustment: Survey Evidence from

Swedish Firms by Mikael Apel, Richard Friberg and Kerstin Hallsten $2001: 128$

Estimating New-Keynesian Phillips Curves on Data with Measurement Errors:

A Full Information Maximum Likelihood Approach by Jesper Lindé......

The Empirical Relevance of Simple Forward- and Backward-looking Models:

A View from a Dynamic General Equilibrium Model by Jesper Lindé .....

Diversification and Delegation in Firms by Vittoria Cerasi and Sonja Daltung

Monetary Policy Signaling and Movements in the Swedish Term Structure of Interest Rates by Malin Andersson, Hans Dillén and Peter Sellin

Evaluation of exchange rate forecasts for the krona's nominal effective exchange rate

by Henrik Degrér, Jan Hansen and Peter Sellin

Identifying the Effects of Monetary Policy Shocks in an Open Economy

by Tor Jacobsson, Per Jansson, Anders Vredin and Anders Warne

Implications of Exchange Rate Objectives under Incomplete Exchange Rate Pass-Through

by Malin Adolfson

Incomplete Exchange Pass-Through and Simple Monetary Policy Rules

by Malin Adolfson

Financial Instability and Monetary Policy: The Swedish Evidence

by U. Michael Bergman and Jan Hansen...

Finding Good Predictors for Inflation: A Bayesian Model Averaging Approach

by Tor Jacobson and Sune Karlsson ............................................................................ 2002:138

How Important Is Precommitment for Monetary Policy?

by Richard Dennis and UIf Söderström

Can a Calibrated New-Keynesian Model of Monetary Policy Fit the Facts?

by Ulf Söderström, Paul Söderlind and Anders Vredin ....

Inflation Targeting and the Dynamics of the Transmission Mechanism by Hans Dillén

Capital Charges under Basel II: Corporate Credit Risk Modelling and the Macro Economy

by Kenneth Carling, Tor Jacobson, Jesper Lindé and Kasper Roszbach

Capital Adjustment Patterns in Swedish Manufacturing Firms: What Model Do They Suggest?

by Mikael Carlsson and Stefan Laséen

Bank Lending, Geographical Distance, and Credit risk: An Empirical Assessment

of the Church Tower Principle by Kenneth Carling and Sofia Lundberg

Inflation, Exchange Rates and PPP in a Multivariate Panel Cointegration Model

by Tor Jacobson, Johan Lyhagen, Rolf Larsson and Marianne Nessén

Evaluating Implied RNDs by some New Confidence Interval Estimation Techniques

by Magnus Andersson and Magnus Lomakka

Taylor Rules and the Predictability of Interest Rates

by Paul Söderlind, Ulf Söderström and Anders Vredin

Inflation, Markups and Monetary Policy

by Magnus Jonsson and Stefan Palmqvist....

Financial Cycles and Bankruptcies in the Nordic Countries by Jan Hansen ................................... 2003:149

Bayes Estimators of the Cointegration Space by Mattias Villani ............................................... 2003:150

Business Survey Data: Do They Help in Forecasting the Macro Economy?

by Jesper Hansson, Per Jansson and Mårten Löf...

The Equilibrium Rate of Unemployment and the Real Exchange Rate:

An Unobserved Components System Approach by Hans Lindblad and Peter Sellin

Monetary Policy Shocks and Business Cycle Fluctuations in a

Small Open Economy: Sweden 1986-2002 by Jesper Lindé .

Bank Lending Policy, Credit Scoring and the Survival of Loans by Kasper Roszbach........ 2003:154 Internal Ratings Systems, Implied Credit Risk and the Consistency of Banks' Risk Classification Policies by Tor Jacobson, Jesper Lindé and Kasper Roszbach 2003:155

Monetary Policy Analysis in a Small Open Economy using Bayesian Cointegrated

Structural VARs by Mattias Villani and Anders Warne

Indicator Accuracy and Monetary Policy: Is Ignorance Bliss? by Kristoffer P. Nimark ........

Intersectoral Wage Linkages in Sweden by Kent Friberg 
The Effects of Permanent Technology Shocks on Labor Productivity

and Hours in the RBC model by Jesper Lindé ....

Credit Risk versus Capital Requirements under Basel II: Are SME Loans and Retail

Credit Really Different? by Tor Jacobson, Jesper Lindé and Kasper Roszbach

Exchange Rate Puzzles: A Tale of Switching Attractors

by Paul De Grauwe and Marianna Grimaldi

Bubbles and Crashes in a Behavioural Finance Model

by Paul De Grauwe and Marianna Grimaldi

Multiple-Bank Lending: Diversification and Free-Riding in Monitoring

by Elena Carletti, Vittoria Cerasi and Sonja Daltung.

Populism by Lars Frisell

Monetary Policy in an Estimated Open-Economy Model with Imperfect Pass-Through

by Jesper Lindé, Marianne Nessén and Ulf Söderström

Is Firm Interdependence within Industries Important for Portfolio Credit Risk?

by Kenneth Carling, Lars Rönnegård and Kasper Roszbach .... $2004: 168$

How Useful are Simple Rules for Monetary Policy? The Swedish Experience

by Claes Berg, Per Jansson and Anders Vredin ....

The Welfare Cost of Imperfect Competition and Distortionary Taxation

by Magnus Jonsson

A Bayesian Approach to Modelling Graphical Vector Autoregressions

by Jukka Corander and Mattias Villani

Do Prices Reflect Costs? A study of the price- and cost structure of retail payment

services in the Swedish banking sector 2002 by Gabriela Guibourg and Biörn Segendorf.

Excess Sensitivity and Volatility of Long Interest Rates: The Role of Limited

Information in Bond Markets by Meredith Beechey

State Dependent Pricing and Exchange Rate Pass-Through

by Martin Flodén and Fredrik Wilander

The Multivariate Split Normal Distribution and Asymmetric Principal

Components Analysis by Mattias Villani and Rolf Larsson

Firm-Specific Capital, Nominal Rigidities and the Business Cycle

by David Altig, Lawrence Christiano, Martin Eichenbaum and Jesper Lindé

Estimation of an Adaptive Stock Market Model with Heterogeneous Agents by Henrik Amilon ..... 2005:177

Some Further Evidence on Interest-Rate Smoothing: The Role of Measurement

Errors in the Output Gap by Mikael Apel and Per Jansson.

Bayesian Estimation of an Open Economy DSGE Model with Incomplete Pass-Through

by Malin Adolfson, Stefan Laséen, Jesper Lindé and Mattias Villani

Are Constant Interest Rate Forecasts Modest Interventions? Evidence from

an Estimated Open Economy DSGE Model of the Euro Area by Malin Adolfson,

Stefan Laséen, Jesper Lindé and Mattias Villani

2005:180

Inference in Vector Autoregressive Models with an Informative

Prior on the Steady State by Mattias Villani

Bank Mergers, Competition and Liquidity by Elena Carletti, Philipp Hartmann

and Giancarlo Spagnolo

Testing Near-Rationality using Detailed Survey Data

by Michael F. Bryan and Stefan Palmqvist 
Sveriges Riksbank 